\title{
Hotplate precipitation gauge calibrations and field measurements
}

\author{
Nicholas Zelasko ${ }^{1}$, Adam Wettlaufer ${ }^{1}$, Bujidmaa Borkhuu ${ }^{1}$, Matthew Burkhart ${ }^{1}$, Leah S. Campbell ${ }^{2}$, \\ W. James Steenburgh ${ }^{2}$, and Jefferson R. Snider ${ }^{1}$ \\ ${ }^{1}$ University of Wyoming Department of Atmospheric Science, Laramie, WY, USA \\ ${ }^{2}$ University of Utah Department of Atmospheric Sciences, Salt Lake City, UT, USA
}

Correspondence: Jefferson R. Snider (jsnider@uwyo.edu)

Received: 13 July 2017 - Discussion started: 30 August 2017

Revised: 30 November 2017 - Accepted: 6 December 2017 - Published: 22 January 2018

\begin{abstract}
First introduced in 2003, approximately 70 Yankee Environmental Systems (YES) hotplate precipitation gauges have been purchased by researchers and operational meteorologists. A version of the YES hotplate is described in Rasmussen et al. (2011; R11). Presented here is testing of a newer version of the hotplate; this device is equipped with longwave and shortwave radiation sensors. Hotplate surface temperature, coefficients describing natural and forced convective sensible energy transfer, and radiative properties (longwave emissivity and shortwave reflectance) are reported for two of the new-version YES hotplates. These parameters are applied in a new algorithm and are used to derive liquidequivalent accumulations (snowfall and rainfall), and these accumulations are compared to values derived by the internal algorithm used in the YES hotplates (hotplate-derived accumulations). In contrast with R11, the new algorithm accounts for radiative terms in a hotplate's energy budget, applies an energy conversion factor which does not differ from a theoretical energy conversion factor, and applies a surface area that is correct for the YES hotplate. Radiative effects are shown to be relatively unimportant for the precipitation events analyzed. In addition, this work documents a $10 \%$ difference between the hotplate-derived and new-algorithmderived accumulations. This difference seems consistent with R11's application of a hotplate surface area that deviates from the actual surface area of the YES hotplate and with R11's recommendation for an energy conversion factor that differs from that calculated using thermodynamic theory.
\end{abstract}

\section{Introduction}

Two types of instrumentation are available for making point measurements of liquid-equivalent snowfall rates and liquidequivalent snow accumulations: (1) weighing gauges and related devices that measure snowfall as it collects in a container or on a surface (Brock and Richardson, 2001; chap. 9), and (2) optical gauges that measure the concentration and size of snow particles either in free fall or within a wind tunnel (Loffler-Mang and Joss, 2000; Deshler, 1988). Many of these gauges obstruct the wind and thus cause falling snow particles to deflect from the measurement zone. Consequently, rates and accumulations are underestimated and should be adjusted to account for undercatch (Jevons, 1861; Lovblad et al., 1993). Alternatively, both gauge types can be operated within a fenced enclosure that minimizes wind and the resultant undercatch (Goodison et al., 1998; Rasmussen et al., 2012). In addition, optical gauges require a snow particle density to convert concentration and size to a liquidequivalent rate and accumulation (Brandes et al., 2007; Lempio et al., 2007). Because this density is variable and difficult to measure accurately (Locatelli and Hobbs, 1974), optical snowfall measurements are uncertain and remain uncertain even if undercatch is accounted for. A further disadvantage for both the weighing and optical devices is that the entrance to the device can become clogged with snow (Warnick, 1954; Currie, 1998; Stickel et al., 2005).

The Yankee Environmental Systems (YES, 2011) hotplate was developed to minimize the aforementioned uncertainties. Advantages of the hotplate are that (1) it is compact, (2) it is immune to clogging, (3) there is no requirement that snow particles fall through an opening, and (4) the derived rates and accumulations are largely independent of snow par- 


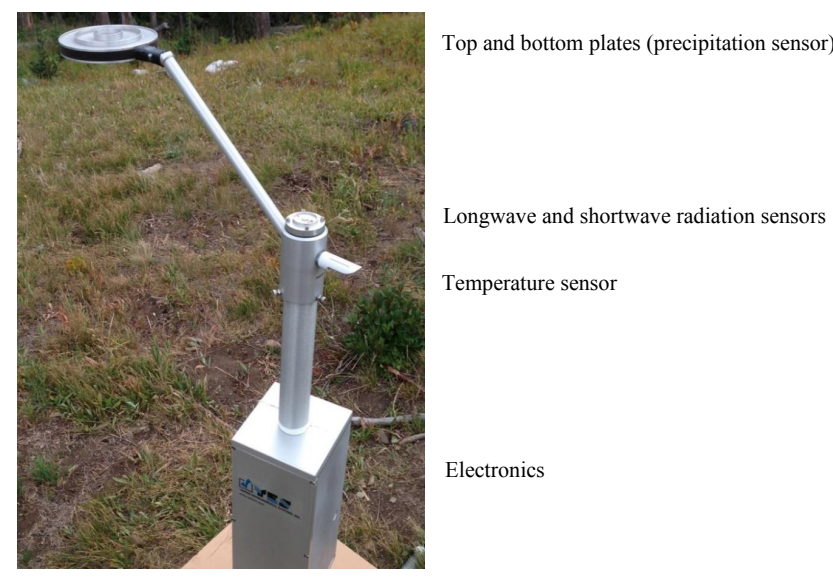

Figure 1. The Yankee Environmental Systems TPS-3100 total precipitation sensor with longwave and shortwave radiation sensors.

ticle density, although a dependence does exist (R11; their Fig. 14). In some applications, a disadvantage of the hotplate relative to a weighing gauge is the hotplate's electrical power consumption. This is $\sim 200 \mathrm{~W}$ in Wyoming during winter.

This work furthers efforts to advance the hotplate as a snowfall measurement system (Borkhuu, 2009; R11; Boudala et al., 2014). We develop calibration constants for two hotplate systems configured with longwave and shortwave radiation sensors. These are a hotplate gauge owned by the University of Wyoming (UW) and by the National Center for Atmospheric Research (NCAR; Boulder, CO) ${ }^{1}$. In addition, we develop a new hotplate data-processing algorithm, derive liquid-equivalent rates and accumulations for 27 precipitation events (snowfall and rainfall), compare accumulations obtained with the new algorithm and those derived by an internal algorithm (hotplate-derived accumulations), and compare accumulations to values derived using weighing gauges.

\section{Algorithm development}

The two stacked circular aluminum plates seen in Fig. 1 are the precipitation measurement portion of the YES hotplate system. The plate diameter $\left(D_{\mathrm{h}}\right)$ is $0.130 \mathrm{~m}$ and both plates have concentric rings that extend vertically either $3 \mathrm{~mm}$ (inner and middle rings) or $1 \mathrm{~mm}$ (outer ring) from the plate surface. One of the plates faces upward and is exposed to precipitation, the other faces downward. Temperature sensors monitor the top and bottom plates and feedback-controlled heaters maintain the plates at approximately $75^{\circ} \mathrm{C}$ (R11). Electrical power supplied to the top plate $\left(Q_{\text {top }}\right)$ compensates

\footnotetext{
${ }^{1}$ When a distinction is needed, we indicate the hotplate, followed by a forward slash, and the location of the deployment. For example, the UW hotplate, deployed at the OWL site, is designated UW/OWL.
}

for energy lost via sensible energy, radiative, and vapor mass transfer. Henceforth, we refer to the latter as latent power output. The hotplate-derived wind speed, evaluated using the "factory calibration" discussed in R11, is used in this analysis. The bottom plate power $\left(Q_{\text {bot }}\right)$ is likely a measurement used in the calculation of that particular wind speed, but this is speculative because the factory wind speed algorithm is proprietary. We symbolize this wind speed as $U$ and use it to evaluate a Reynolds number $(R e)$, and use the latter to parameterize sensible energy transfer from the ventilated surface of the top plate. R11 also derived wind speeds by fitting $Q_{\text {bot }}$, ambient temperature, and a wind speed measured at $10 \mathrm{~m}$ above ground level (a.g.1.). This wind speed is not used in this analysis. The hotplate ambient temperature $(T)$ measurement comes from the sensor seen below the radiation instruments (Fig. 1), the relative humidity (RH) measurement comes from a sensor that protrudes below the electronics box (Fig. 1), and the hotplate pressure sensor is contained within the electronics box. A complete description of our nomenclature is provided in the Appendix.

Since the hotplate was introduced in 2003, two teams (Borkhuu, 2009; R11) have reported data-processing algorithms. The algorithm in Borkhuu (2009) can be explained by reference to the equation she used to model the top plate's power budget:

$$
\begin{array}{ll}
0= & \begin{array}{l}
\text { Implied steady-state } \\
Q_{\text {top }}
\end{array} \\
-D_{\mathrm{h}} \cdot K_{x} \cdot & \begin{array}{l}
\text { Electrical power supplied to } \\
\text { top plate }
\end{array} \\
\left(T_{\mathrm{h}}-T\right) \cdot\left(\gamma+\alpha \cdot R e^{\beta}\right) & \text { Sensible power output } \\
-P \cdot E / f_{2} & \text { Latent power output. }
\end{array}
$$

In Eq. (1), there are three terms that sum to zero in an assumed steady-state. The last of these, the latent power output, is proportional to the precipitation rate $(P)$ and a snow particle catch efficiency $(E)$ and inversely proportional to $f_{2}$, an electrical-to-precipitation conversion factor. Also, in Eq. (1), the sensible power output has contributions from natural convection (proportional to $\gamma$ ) and forced convection (proportional to $\alpha \cdot R e^{\beta}$ ), where $\alpha, \beta$, and $\gamma$ are fitted constants. These convective regimes are discussed in Kobus and Wedekind (1995) and are shown graphically in their Fig. 6. Equation (1) is similar to the algorithm used by King et al. (1978) to derive cloud liquid water concentration using a heated airborne sensor.

The algorithm in R11 is based on Eq. (2).

$$
P=\left[Q_{\text {top }}-Q_{\text {bot }}-f_{1}(U)\right] \cdot f_{2} / E
$$

Here, $f_{1}(U)$ is a wind-speed-dependent function. Also, in Eq. (2), we see the conversion factor introduced in the previous paragraph. Somewhat different from how R11 formulated their conversion factors for rain and snow, we formulated $f_{2}$ to account for the warming of ice, melting, warming 
of the liquid, and liquid evaporation. For rain, we formulated $f_{2}$ to account for the warming of liquid and its evaporation. With an exception that we justify later, we applied the conversion factors as recommended by R11: (1) if $T<0^{\circ} \mathrm{C}$, the snow $f_{2}$ is applied, and (2) if $T>4{ }^{\circ} \mathrm{C}$ the rain $f_{2}$ is applied.

In Eq. (1), the sensible power output is a function of $R e$, and thus $U$, and also a function of $T$. Hence, Eq. (1) can be rearranged to look similar to Eq. (2) with $P$ dependent on $T$, $U, Q_{\text {top }}, f_{2}$, and $E$. A difference between the formulations of Eqs. (1) and (2) is the explicit dependence on $Q_{\text {bot }}$ in Eq. (2); this is in addition to the implicit $Q_{\text {bot-dependent wind speed }}$ in $R e$ (Eq. 1) and in $f_{1}(U)$ (Eq. 2).

Borkhuu (2009), YES (2011), and R11 surmised that the energetic effect of longwave and shortwave radiation could, in some settings, be comparable to the latent power output. Consequently, our hotplate (Wolfe and Snider, 2012) was upgraded to firmware version 3.1.2 in 2011. The upgrade included radiation sensors for the measurement of downwelling longwave and shortwave fluxes. An objective of this paper is the incorporation of the radiation measurements into a new precipitation rate algorithm.

We used the following equation to analyze the top plate's power budget:

$\begin{array}{ll}0= & \begin{array}{l}\text { Implied steady-state } \\ Q_{\text {top }}\end{array} \\ & \begin{array}{l}\text { Electrical power supplied to } \\ \text { top plate }\end{array} \\ -D_{\mathrm{h}} \cdot K_{x} \cdot & \\ \left(T_{\mathrm{h}}-T\right) \cdot\left(\gamma+\alpha \cdot R e^{\beta}\right) & \text { Sensible power output } \\ -A_{\mathrm{h}} \cdot \varepsilon_{\mathrm{h}} \cdot \sigma \cdot T_{\mathrm{h}}^{4} & \text { Longwave power output } \\ +A_{\mathrm{h}} \cdot \varepsilon_{\mathrm{h}} \cdot \mathrm{IR}_{\mathrm{d}} & \text { Longwave power input } \\ +A_{\mathrm{h}} \cdot\left(1-R_{\mathrm{h}}\right) \cdot \mathrm{SW} & \text { Shortwave power input } \\ -P \cdot E / f_{2} & \text { Latent power output. }\end{array}$

Compared to Eq. (1), Eq. (3) has three additional terms. These describe the interaction of the top plate with its environment via radiative transfer. Two of these terms are inputs (longwave and shortwave) and one is an output (longwave).

\subsection{Hotplate data files}

The hotplate outputs data to two files. The previously discussed $Q_{\text {top }}$ and $Q_{\text {bot }}$ are two of several recorded variables and both of these are essential for the analysis described here. One of the files is known as the UHP or "user" hotplate file. The UHP file is provided to all YES customers. The second file is the SHP or "sensor" file. The SHP file is proprietary but we were granted access to it by NCAR. Table 1 has the list of all recorded variables and how some of these are symbolized. A complete list of variables (measured and computed) and constants is provided in the Appendix. With the exception of Unix time, all variables in Table 1 are provided as $60 \mathrm{~s}$ averages, sampled at $1 \mathrm{~Hz}$ (YES, 2011).

\subsection{Radiative properties}

Two radiative properties are applied in our analysis of the top plate's power budget (Eq. 3). In the infrared, or longwave, the emissivity of the top plate is the key property. The material used to fabricate the plates is aluminum, which when exposed to air becomes covered with an aluminum oxide layer. Hence, the hotplate emissivity was taken to be that of oxidized aluminum $\left(\varepsilon_{\mathrm{h}}=0.14\right.$; Weast, 1975; Sect. E). Furthermore, we made two assumptions: (1) the longwave output (Eq. 3) is the product of $\varepsilon_{\mathrm{h}}$, the hotplate area $\left(A_{\mathrm{h}}\right)$, and the flux emitted by a black body at $T_{\mathrm{h}}$, and (2) the longwave input (Eq. 3) is the product $\varepsilon_{\mathrm{h}}, A_{\mathrm{h}}$ and the downwelling longwave flux $\left(I_{d}\right)$. In a later section, we explain how we derive $I_{d}$.

In the visible, or shortwave, the top plate's reflectance $\left(R_{\mathrm{h}}\right)$ is the key property. Equation (3) shows how we factored into the power budget the top plate's reflectance, a measured downwelling shortwave flux (SW; Table 1), and $A_{\mathrm{h}}$. A value for $R_{\mathrm{h}}$ was determined as follows. We exposed the UW hotplate to solar illumination while measuring the solar flux and then shaded the hotplate to establish a baseline for the determination of $R_{\mathrm{h}}$. During these experiments, there was negligible wind and therefore natural convection dominated forced convection in the budget. The budget equation we used to analyze these measurements has three terms: $Q_{\text {top }}$, sensible power output, and solar input. In two experiments, the values $R_{\mathrm{h}}=0.66$ and $R_{\mathrm{h}}=0.61$ were derived. We apply the average of these $\left(R_{\mathrm{h}}=0.63\right)$ in our analysis of measurements from both UW and NCAR hotplates. Because of the oxide layer, the derived reflectance is smaller than the value reported for polished aluminum reflecting "incandescent" light (0.69; Weast, 1975; Sect. E) and significantly smaller than the value for vacuum-deposited aluminum at visible wavelengths (0.97; Hass, 1955).

\section{Methods}

\subsection{Temperature measurements}

Ice bulb temperatures at OWL were calculated using temperature, $\mathrm{RH}$, and pressure measurements made within a fully shielded housing (Steenburgh et al., 2014). At GLE and BTL ice bulb temperatures were calculated using the hotplate-derived temperature, $\mathrm{RH}$, and pressure values (Table 1). Because the hotplate temperature sensor is incompletely shielded (Fig. 1), there is concern that its measurement is positively biased by solar heating. We investigated this by differencing hotplate-derived temperatures acquired during precipitation events at OWL and values acquired by the fully shielded temperature sensor operated at OWL. On average, the hotplate values were larger $\left(0.4 \pm 0.4^{\circ} \mathrm{C}\right)$. We did not attempt to correct for this bias. 
Table 1. Hotplate data files.

\begin{tabular}{|c|c|c|c|}
\hline Recorded variable $^{\mathrm{a}}$, unit & File & File & Symbol \\
\hline & UHP & SHP & \\
\hline Unix time, $\mathrm{s}$ & $\checkmark$ & $\checkmark$ & \\
\hline Liquid-equivalent precipitation rate, $\mathrm{mm} \mathrm{h}^{-1}$ & $\checkmark$ & & $P_{\text {YES }}$ \\
\hline Accumulated liquid-equivalent precipitation, $\mathrm{mm}$ & $\checkmark$ & & \\
\hline Ambient temperature, ${ }^{\circ} \mathrm{C}$ & $\checkmark$ & $\checkmark$ & $T$ \\
\hline Enclosure temperature, ${ }^{\circ} \mathrm{C}$ & $\checkmark$ & $\checkmark$ & \\
\hline Wind speed, $\mathrm{m} \mathrm{s}^{-1}$ & $\checkmark$ & & $U$ \\
\hline Downwelling shortwave flux, $\mathrm{W} \mathrm{m}^{-2}$ & $\checkmark$ & $\checkmark$ & SW \\
\hline Longwave radiation measurement, $\mathrm{W} \mathrm{m}^{-2}$ & $\checkmark$ & $\checkmark$ & $M_{\mathrm{IR}}$ \\
\hline Barometric pressure, $\mathrm{hPa}$ & $\checkmark$ & $\checkmark$ & $p^{\mathrm{b}}$ \\
\hline Relative humidity sensor temperature, ${ }^{\circ} \mathrm{C}$ & $\checkmark$ & $\checkmark$ & \\
\hline Relative humidity, $\%$ & $\checkmark$ & $\checkmark$ & RH \\
\hline Top plate voltage, $\mathrm{V}$ & & $\checkmark$ & \\
\hline Bottom plate voltage, $\mathrm{V}$ & & $\checkmark$ & \\
\hline Top plate current, A & & $\checkmark$ & \\
\hline Bottom plate current, A & & $\checkmark$ & \\
\hline Top plate resistance, $\Omega$ & & $\checkmark$ & \\
\hline Bottom plate resistance, $\Omega$ & & $\checkmark$ & \\
\hline Top plate power, $\mathrm{W}$ & & $\checkmark$ & $Q_{\text {top }}$ \\
\hline Bottom plate power, $\mathrm{W}$ & & $\checkmark$ & $Q_{\text {bot }}$ \\
\hline Radiation sensors' temperature, ${ }^{\circ} \mathrm{C}$ & & $\checkmark$ & \\
\hline
\end{tabular}

${ }^{a}$ With the exception of Unix time, all recorded variables are $60 \mathrm{~s}$ running averages, sampled at $1 \mathrm{~Hz}$ (YES, 2011). ${ }^{\mathrm{b}}$ Although pressure is a recorded variable, the pressure used in the UW algorithm ( $p_{x}$; Sect. 3.7 and Appendix) is the standard-atmosphere pressure at the altitude of the measurement.

\subsection{Site description}

Indoor testing was conducted in a high-bay weather balloon hangar and in a laboratory. These facilities are at the University of Wyoming (UW) and are referred to as hangar and lab. During wintertime, and especially at night, the hangar is cold $\left(\sim 0{ }^{\circ} \mathrm{C}\right)$; the lab is warm year-round $\left(\sim 20^{\circ} \mathrm{C}\right)$. Field measurements (Table 2 ) were conducted in southeastern Wyoming at the Glacier Lakes Ecosystem Experiments Site (GLE), in southeastern Wyoming near the summit of Battle Pass (BTL), and at the northern Redfield site in western New York (OWL). During both indoor and field measurements, all parameters reported by the hotplate (UHP and SHP variables; Sect. 2.1) were recorded using a custom-built data system.

The accuracy of a hotplate-estimated precipitation rate depends on whether the sensed hydrometeors are rain or snow (R11). We infer the presence of rain or snow using a calculated ice bulb temperature $\left(T_{\mathrm{IB}}\right)$ (Iribarne and Godson, 1981; chap. 7). Measurements used to derive the $T_{\mathrm{IB}} \mathrm{S}$ are described in Sect. 3.1. The lower limits on these derived values, assuming the measured $\mathrm{RH}$ is overestimated by $5 \%$ (YES, 2011), is no more than $0.4{ }^{\circ} \mathrm{C}$ colder than the values we report. In instances with $T_{\mathrm{IB}} \mathrm{s}$ larger than $0{ }^{\circ} \mathrm{C}$, we assume the sensed hydrometeors were liquid.

\subsection{NOAH-II gauge}

The NOAH-II is a weighing-type gauge manufactured by ETI Instrument Systems Inc. (www.etisensors.com). NCAR operated a NOAH-II at GLE and BTL during 2012, and coauthors (Campbell and Steenburgh) operated a NOAH-II at OWL (December 2013 to January 2014; Campbell et al., 2016). The three NOAH-II gauges were outfitted with Alter shields (Goodison et al., 1998; hereafter G98).

\subsection{Indoor testing}

Indoor testing of the UW hotplate was conducted every year from 2011 to 2015; the NCAR hotplate was only tested in 2012. Based on our testing of the UW hotplate, we have no evidence indicating that the calibration changed over the duration of any of the field deployments; however, Wettlaufer (2013) demonstrates that calibration constants did change over the 2011 to 2015 interval and likely in response to servicing conducted twice at YES. In this paper we present calibration constants appropriate for the UW hotplate sensor deployed at GLE (April 2012) and at OWL (December 2013 to January 2014).

During testing, we controlled the hotplate's radiation environment by placing a material with known emissivity (painted-steel sheeting, $\varepsilon_{\mathrm{s}}=0.84$ ) above and below the hotplate. The steel sheets were positioned to dominate the hot- 
Table 2. Field sites, site location, vegetation at the site, gauge location, number of events, and event type.

\begin{tabular}{|c|c|c|c|c|}
\hline $\begin{array}{l}\text { Site abbreviation, } \\
\text { site reference, } \\
\text { hotplate }\end{array}$ & $\begin{array}{l}\text { Site } \\
\text { location }\end{array}$ & $\begin{array}{l}\text { Height } \\
\text { of } \\
\text { vegetation, } \\
\text { ma.g.l. }\end{array}$ & Gauge location at site & $\begin{array}{l}\text { Precipitation } \\
\text { events }\end{array}$ \\
\hline $\begin{array}{l}\text { GLE } \\
\text { Wettlaufer (2013) } \\
\text { UW }\end{array}$ & $\begin{array}{l}\text { SE Wyoming } \\
106.240^{\circ} \mathrm{W} \\
41.3665^{\circ} \mathrm{N} \\
3190 \mathrm{~m}\end{array}$ & 10 to $20 \mathrm{~m}$ & $\begin{array}{l}\text { Hotplate: } 27 \mathrm{~m} \text { a.g.l. on top deck of a meteorolog- } \\
\text { ical tower } \\
\text { NOAH-II: } 3 \text { ma.g.l. (clearing in conifer forest } \\
80 \mathrm{~m} \text { SE of tower) }\end{array}$ & 1 snow \\
\hline $\begin{array}{l}\text { BTL } \\
\text { Wettlaufer (2013) } \\
\text { NCAR }\end{array}$ & $\begin{array}{l}\text { SE Wyoming } \\
106.975^{\circ} \mathrm{W} \\
41.1558^{\circ} \mathrm{N} \\
3010 \mathrm{~m}\end{array}$ & 10 to $20 \mathrm{~m}$ & $\begin{array}{l}\text { Clearing in conifer forest } \\
\text { Hotplate: } 3 \mathrm{~m} \text { a.g.l. } \\
\text { NOAH-II: } 3 \mathrm{~m} \text { a.g.l. }\end{array}$ & 3 snow \\
\hline $\begin{array}{l}\text { OWL } \\
\text { Steenburgh et al. (2014) } \\
\text { UW }\end{array}$ & $\begin{array}{l}\text { NW New York } \\
75.8771^{\circ} \mathrm{W} \\
43.6245^{\circ} \mathrm{N} \\
385 \mathrm{~m}\end{array}$ & 2 to $5 \mathrm{~m}$ & $\begin{array}{l}\text { Clearing in deciduous brush and deciduous trees } \\
\text { Hotplate: } 1.7 \mathrm{~m} \text { a.g.1. }{ }^{\mathrm{b}} \text { and } 2.5 \mathrm{~m} \text { a.g.1. }{ }^{\mathrm{c}} \\
\text { NOAH-II: } 2.5 \mathrm{~m} \text { a.g.1. }\end{array}$ & $\begin{array}{l}4 \text { rain } \\
19 \text { snow }\end{array}$ \\
\hline
\end{tabular}

a This is the Brooklyn Lake, Wyoming AmeriFlux Tower; AmeriFlux is a network of sites that measure energy and trace-gas transfers. ${ }^{\mathrm{b}}$ First 7 of 23 OWL precipitation events (date $<17$ December 2013) ${ }^{\mathrm{c}}$ Last 16 of 23 OWL precipitation events (date $<17$ December 2013).

plate's upward and downward fields of view (Fig. 2); however, the sheets were positioned so that they were not heated by the hotplate. In that case, the sheet temperature $\left(T_{\mathrm{s}}\right)$ can be assumed equal to $T$.

\subsection{Downwelling longwave flux}

As we have already mentioned, previous work concluded that the hotplate method of determining precipitation can be affected by longwave radiation. In response to that finding, newer versions of the hotplate have a device that measures longwave radiation (pyrgeometer, e.g., Albrecht et al., 1974) (Fig. 1 and Table 1).

$$
M_{\mathrm{IR}}=\mathrm{IR}_{\mathrm{d}}-\mathrm{IR}_{\mathrm{u}}
$$

The left-hand side of Eq. (4) represents the longwave measurement $\left(M_{\mathrm{IR}}\right)$ and the right-hand side has the downwelling and upwelling components contributing to $M_{\mathrm{IR}}$.

Because $\mathrm{IR}_{\mathrm{d}}$ appears in the top plate's power budget (Eq. 3), and since $M_{\mathrm{IR}}$ is the only term in Eq. (4) that is measured, the upwelling component $\left(\mathrm{IR}_{\mathrm{u}}\right)$ must be evaluated. This is possible because the signal from the pyrgeometer is adjusted within the hotplate electronics package to make the source of the upwelling flux a virtual blackbody at the ambient temperature (YES, personal communication, 2012). In that case, $\mathrm{IR}_{\mathrm{d}}$ can be formulated as

$$
\mathrm{IR}_{\mathrm{d}}=M_{\mathrm{IR}}+\sigma \cdot T^{4},
$$

where $\sigma$ is the Stefan-Boltzmann constant and $T$ is the hotplate-measured ambient temperature. We also use Eq. (6) to calculate the downwelling longwave flux.

$\mathrm{IR}_{\mathrm{d}}=\varepsilon_{\mathrm{s}} \cdot \sigma \cdot T_{\mathrm{s}}^{4}$

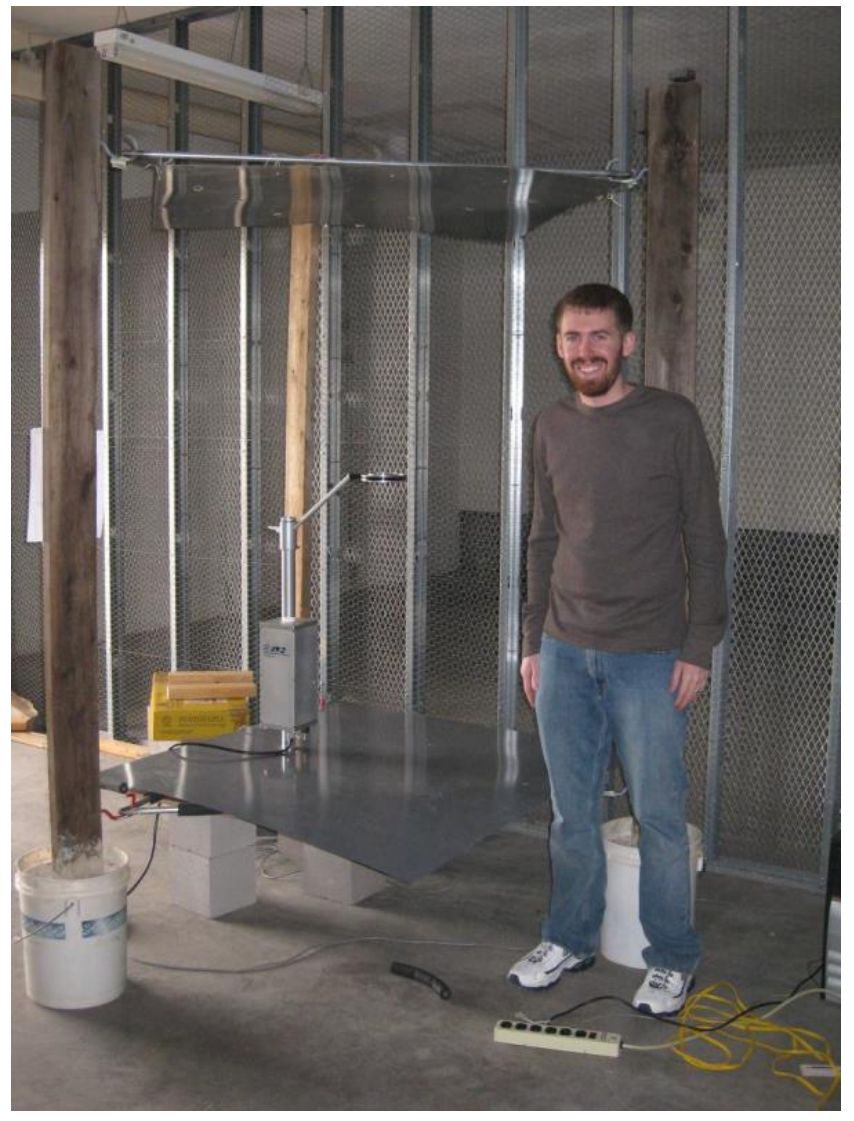

Figure 2. Picture taken during indoor testing showing a hotplate's precipitation sensor positioned between the top and bottom paintedsteel sheets. 
Table 3. Summary of warm-cold tests.

\begin{tabular}{llcc}
\hline \multicolumn{4}{l}{ Indoor calibration (warm-cold tests) } \\
\hline Year & Hotplate/field site & $T_{\mathrm{h}},{ }^{\circ} \mathrm{C}$ & $\gamma$ \\
\hline 2012 & NCAR/BTL & $42.2 \pm 7.4^{*}$ & $106 . \pm 15.1^{*}$ \\
$2012-2013$ & UW/GLE & $52.2 \pm 15.7$ & $74.8 \pm 18.1$ \\
$2013-2015$ & UW/OWL & $66.5 \pm 7.8$ & $57.8 \pm 7.7$ \\
\hline * Error limits derived by perturbing $Q$ top,w (i.e., the value acquired in the warm test) \\
by $\pm 0.5 \mathrm{~W}$ and repeating the analysis based on Eqs. (7a)-(7b).
\end{tabular}

\subsection{Warm-cold ambient temperature tests}

Procedures described here were applied during testing conducted indoors (hangar and lab, Sect. 3.2) at two different temperatures and are hereafter referred to as the warm-cold test. We show how values of a warm $\left(T_{\mathrm{w}}\right)$ and cold $\left(T_{\mathrm{c}}\right)$ ambient temperature, combined with other recorded hotplate variables (Table 1), can be used to derive two calibration parameters in Eq. (3) ( $T_{\mathrm{h}}$ and $\left.\gamma\right)$. In our analysis, the temperature of the steel sheeting $\left(T_{\mathrm{S}}\right)$ was assumed equal to the ambient temperature (either $T_{\mathrm{w}}$ or $T_{\mathrm{c}}$ ) and $\mathrm{IR}_{\mathrm{d}}$ was calculated using Eq. (6). By design these tests had negligible forcedconvective and latent energy transfers. In that case, Eqs. (7a)(7b) are the top plate budget equations.

$$
\begin{aligned}
0 & =Q_{\text {top }, \mathrm{w}}-D_{\mathrm{h}} \cdot K_{x} \cdot\left(T_{\mathrm{h}}-T_{\mathrm{w}}\right) \cdot \gamma-A_{\mathrm{h}} \cdot \varepsilon_{\mathrm{h}} \cdot \sigma \cdot T_{\mathrm{h}}^{4} \\
& +A_{\mathrm{h}} \cdot \varepsilon_{\mathrm{h}} \cdot \varepsilon_{\mathrm{s}} \cdot \sigma \cdot T_{\mathrm{w}}^{4}+A_{\mathrm{h}} \cdot\left(1-R_{\mathrm{h}}\right) \cdot \mathrm{SW}_{\mathrm{w}} \\
0 & =Q_{\mathrm{top}, \mathrm{c}}-D_{\mathrm{h}} \cdot K_{x} \cdot\left(T_{\mathrm{h}}-T_{\mathrm{c}}\right) \cdot \gamma-A_{\mathrm{h}} \cdot \varepsilon_{\mathrm{h}} \cdot \sigma \cdot T_{\mathrm{h}}^{4} \\
& +A_{\mathrm{h}} \cdot \varepsilon_{\mathrm{h}} \cdot \varepsilon_{\mathrm{s}} \cdot \sigma \cdot T_{\mathrm{c}}^{4}+A_{\mathrm{h}} \cdot\left(1-R_{\mathrm{h}}\right) \cdot \mathrm{SW}_{\mathrm{c}}
\end{aligned}
$$

The measurements applied in these equations were $T_{\mathrm{w}}$ and $T_{\mathrm{c}}$, the warm and cold plate powers $\left(Q_{\text {top,w }}\right.$ and $\left.Q_{\text {top,c }}\right)$, the warm and cold shortwave fluxes $\left(\mathrm{SW}_{\mathrm{w}}\right.$ and $\left.\mathrm{SW}_{\mathrm{c}}\right)$, and the constants (Appendix). Values of $T_{\mathrm{h}}$ and $\gamma$ (hereafter referred to as $T_{\mathrm{h}} / \gamma$ pairs) were derived by minimizing departures from zero simultaneously in Eqs. (7a)-(7b). Minimization was conducted using a Newton's method equation solver (Exelis Visual Information Solutions, Inc.); the convergence tolerance was $1 \cdot 10^{-4} \mathrm{~J} \mathrm{~s}^{-1}$.

\subsection{Nusselt-Reynolds relationship}

The Nusselt number $\left(N u=\gamma+\alpha \cdot R e^{\beta}\right)$, is a component of the sensible power output term in Eq. (3). In this section, we develop a relationship between $N u$ and $R e$ based on measurements recorded in the field when precipitation was not occurring; in a later section we show how that relationship was applied in the new algorithm.

Conceptually, $N u$ is a dimensionless representation of the sensible power output. Equation (8a) was used to calculate $N u$ with measurements $\left(Q_{\text {top }}, T\right.$, and $\left.\mathrm{SW}\right)$, a calculated vari- able ( $\operatorname{IR}_{\mathrm{d}}$; Sect. 3.5), and constants (Appendix and Table 3).

$$
\begin{aligned}
N u & =\left[Q_{\mathrm{top}}-A_{\mathrm{h}} \cdot \varepsilon_{\mathrm{h}} \cdot \sigma \cdot T_{\mathrm{h}}^{4}+A_{\mathrm{h}} \cdot \varepsilon_{\mathrm{h}} \cdot \mathrm{IR}_{\mathrm{d}}\right. \\
& \left.+A_{\mathrm{h}} \cdot\left(1-R_{\mathrm{h}}\right) \cdot \mathrm{SW}\right] /\left[D_{\mathrm{h}} \cdot K_{x} \cdot\left(T_{\mathrm{h}}-T\right)\right]
\end{aligned}
$$

In the numerator are the terms contributing to the sensible power output, and in the denominator is a term proportional to the sensible power due to molecular conduction.

Conceptually, the Reynolds number $R e$ (Sect. 2) is a dimensionless representation of the wind speed. Equation (8b) was used to calculate $R e$ with a measurement $(U)$ and the constants (Appendix).

$$
R e=p_{x} \cdot D_{\mathrm{h}} \cdot U /\left(R_{\mathrm{d}} \cdot T_{x} \cdot \mu_{x}\right)
$$

Two criteria were used to select a site-specific data subset for the $N u-R e$ development: (1) no precipitation, and (2) at least $3 \mathrm{~h}$ of continuous measurements with a broad range of wind speeds. We fitted the selected $\mathrm{Nu}-\mathrm{Re}$ pairs using a nonlinear least squares procedure (curvefit; Exelis Visual Information Solutions, Inc.); the convergence tolerance for the relative decrease in chi-squared was $1 \cdot 10^{-3}$.

\subsection{Electrical-to-precipitation conversion factor}

Equilibrium thermodynamics, with the assumptions that ice melts at $T_{o}=0{ }^{\circ} \mathrm{C}$ and vaporization occurs at $T_{\mathrm{h}}$, was used to derive the conversion factor in Eq. (3) $\left(f_{2}\right)$. Adopting the temperature criteria from R11 (also see Sect. 2) and a framework from Iribarne and Godson (1981; chap. 7), we formulated the theoretical conversion factors as

$$
\begin{aligned}
f_{2}\left(T, T_{\mathrm{h}}\right) & =\left\{\rho \cdot A _ { \mathrm { h } } \cdot \left[C_{i} \cdot\left(T_{o}-T\right)+L_{\mathrm{f}}\left(T_{o}\right)\right.\right. \\
& \left.\left.+C \cdot\left(T_{\mathrm{h}}-T_{o}\right)+L_{\mathrm{v}}\left(T_{\mathrm{h}}\right)\right]\right\}^{-1}\left(T<0^{\circ} \mathrm{C}\right) \\
f_{2}\left(T, T_{\mathrm{h}}\right) & =\left\{\rho \cdot A _ { \mathrm { h } } \cdot \left[C \cdot\left(T_{\mathrm{h}}-T\right)\right.\right. \\
& \left.\left.+L_{\mathrm{V}}\left(T_{\mathrm{h}}\right)\right]\right\}^{-1}\left(T>4{ }^{\circ} \mathrm{C}\right) .
\end{aligned}
$$

This formulation is graphed in Fig. 3a (solid line) where we extended Eq. (9b) into the temperature range $\left(0{ }^{\circ} \mathrm{C}<T<4{ }^{\circ} \mathrm{C}\right)$ where the distinction between rain and snow is ambiguous (R11).

We now compare the conversion factor derived using Eqs. (9a)-(9b) with that reported in R11. To be consistent with R11, we assume $T=T_{\mathrm{h}}=0^{\circ} \mathrm{C}$. We find that the ratio of $f_{2}$ (Eq. 9a) divided by the factor reported in R11 for snow $\left(3.99 \cdot 10^{-8} \mathrm{~m} \mathrm{~J}^{-1}\right)$ and the ratio of $f_{2}$ (Eq. $9 \mathrm{~b}$ ) divided by the factor reported in $\mathrm{R} 11$ for rain $\left(4.52 \cdot 10^{-8} \mathrm{~m} \mathrm{~J}^{-1}\right)$ are both 0.666 . Since these ratios are equal to the area in R11 $\left(A_{\mathrm{h}}=0.008844 \mathrm{~m}^{2}\right)$, divided by the area applied in our calculation $\left(A_{\mathrm{h}}=(\pi / 4) \cdot 0.130^{2}=0.01327 \mathrm{~m}^{2}\right)$, we conclude that the discrepancy is not due to differing thermodynamic parameters applied in R11 and our calculations (e.g., the latent heat of vaporization); rather it stems from the different values used for the hotplate area. Further, R11 changed their theoretical $f_{2}$ to an actual conversion factor that was 
Table 4. Summary of drip tests.

\begin{tabular}{llrrr}
\hline \multicolumn{4}{c}{ Indoor calibration (drip tests) } \\
\hline Year & Hotplate/field site & $P_{\text {REF vs. }}<P_{\text {UW }}>$ ratio $^{\mathrm{a}}$ & $P_{\text {REF Vs. }}<P_{\text {YES }>\text { ratio }^{\mathrm{a}}}$ & $\#^{\mathrm{b}}$ \\
\hline 2012 & NCAR/BTL & $0.99 \pm 0.02$ & $0.81 \pm 0.03$ & 6 \\
$2012-2013$ & UW/GLE & $1.00 \pm 0.06$ & $0.84 \pm 0.05$ & 6 \\
$2013-2015$ & UW/OWL & $0.97 \pm 0.04$ & $0.79 \pm 0.03$ & 6 \\
\hline
\end{tabular}

a Ratios were derived as the slope of a regression lines forced through the origin. The $x$ deviations (horizontal departures of data from regression line) were used as the basis for the least squares criterion of best fit (Young, 1962). Standard deviations on the fitted ratios (confidence intervals) were derived using Student's $t$ distribution at the $95 \%$ level (Havilcek and Crain, 1988). $\mathrm{b}_{\#}=$ number of tests.
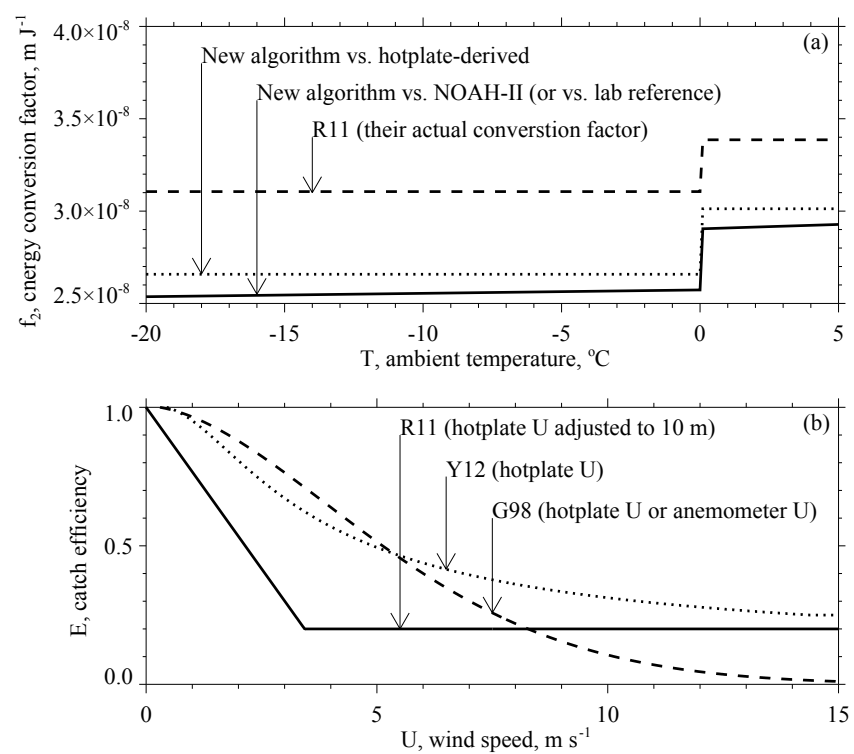

Figure 3. (a) Electrical-to-precipitation conversion factors vs. ambient temperature assuming snow at $T<0^{\circ} \mathrm{C}$ and rain at $T>0{ }^{\circ} \mathrm{C}$. See text for details. (b) Snow particle catch efficiency vs. wind speed using the R11, Y12, and G98 formulations discussed in the text.

"... lower because of the imperfect heat transfer from the precipitation to the hot plate (losses to the air, e.g.)." We do not find justification for this in R11, nor do we agree with R11's assignment of $A_{\mathrm{h}}=0.008844 \mathrm{~m}^{2}$, assuming they were recommending that value for the hotplate sold by YES. Recently, Boudala et al. (2014) addressed the second of these two points, making it clear that $A_{\mathrm{h}}=0.01327 \mathrm{~m}^{2}$ is appropriate for the hotplate sold by YES.

In light of the above, the ratio of our $f_{2}$ (Eqs. 9a-9b with $T=T_{\mathrm{h}}=0{ }^{\circ} \mathrm{C}$ ) divided by the actual conversion factor in $\mathrm{R} 11$ is 0.86 for snow and 0.89 for rain. Since a derived precipitation rate is proportional to $f_{2}$ (e.g., Eq. 2), we expect the ratio of a precipitation rate from the new algorithm (assuming $T=T_{\mathrm{h}}=0{ }^{\circ} \mathrm{C}$ ) divided by a synchronous hotplatederived precipitation rate to be between 0.86 and 0.89 . Our expectation hinges on the assumption that the YES algorithm has incorporated R11's surface area and R11's distinction between theoretical and actual conversion factors.

We calculate $f_{2}$ in the new algorithm two ways: (1) in a comparison to a hotplate-derived accumulation, our $f_{2}$ is set to $2.66 \cdot 10^{-8} \mathrm{~m} \mathrm{~J}^{-1}$ (snow) and $3.01 \cdot 10^{-8} \mathrm{~m} \mathrm{~J}^{-1}$ (rain). These values were obtained from Eqs. (9a)-(9b) with $T=T_{\mathrm{h}}=$ $0{ }^{\circ} \mathrm{C}$ and are displayed as a dotted line in Fig. 3a. (2) In comparisons to either a NOAH-II accumulation or to a laboratory reference precipitation rate, we evaluate $f_{2}$ using Eqs. (9a)(9b) with a $T_{\mathrm{h}}$ from Table 3 and with the hotplate-measured ambient $T$ (Table 1). In addition to the step change due to the difference between the latent heats of sublimation and vaporization, our conversion factor has a weak temperature dependence (Fig. 3a, solid line). This is due to the warming discussed in Sect. 2. Also, in Fig. 3a we display the actual conversion factor from R11 (dashed line). Our classification of measurements into snow and rain is discussed in a later section.

\subsection{Snow particle catch efficiency}

In this section, we evaluate a wind-speed-dependent function and use it to account for the top plate's snow particle catch efficiency $(E$; Sect. 2$)$. The physical processes this function accounts for are (1) snow particle bouncing subsequent to collision with the top plate, followed by transfer away from the top plate by wind, and (2) shearing off of a snow particle after it has landed on the top plate (R11). This conceptual description of catch on the hotplate is different from that used to describe catch by weighing gauges where undercatch results because a subset of snow particles are carried over the gauge by a vertically accelerated flow (Nespor and Servuk, 1999; Thériault et al., 2012). Both R11 and G98 derive catch efficiencies as the ratio of two paired values of liquid-equivalent accumulation, one obtained from the gauge of interest and the other obtained from a second gauge operated inside a Double Fence Intercomparison Reference shield (DFIR).

The snow particle catch efficiency functions applied here are both gauge and location specific. For the UW hotplate (at GLE and OWL), and the NCAR hotplate (at BTL), we apply the function recommended by YES (YES, personal communication, 2012; hereafter Y12). Wind speeds used in the ef- 
ficiency calculation are the hotplate-derived $U$. In addition, the hotplate catch efficiency function described by R11 (their Eq. 6) was also applied. This was based on the hotplate $U$ adjusted to the $10 \mathrm{~m}$ level with a roughness length $z_{o}=0.3 \mathrm{~m}$ (G98, their Eq. 4.3.1) and was only used in analyses of measurements made at OWL. The $z_{o}$ we picked corresponds to a surface with "Many trees, hedges, few buildings" (Panofsky and Dutton, 1984; their Table 6.2). This assignment is consistent with the presence of shrubs and trees (Steenburgh et al., 2014) and a two-story barn at the OWL site. The barn was located at the eastern edge of a fallow field, $80 \mathrm{~m}$ west of the gauges at OWL. For the NOAH-II gauge, we applied a function developed for an 8 inch $(0.20 \mathrm{~m}$; diameter) Altershielded gauge (G98; their Eq. 4.7.1). Wind speeds used in that calculation are from the hotplate (at GLE and BTL) or from an anemometer (at OWL) (Campbell et al., 2016). Of course, we are assuming that the function from G98 mimics undercatch by our 12 inch $(0.30 \mathrm{~m}$; diameter $)$ Alter-shielded NOAH-II gauge.

In Fig. 3b, we present the three catch efficiency functions (R11 with $U$ adjusted to $10 \mathrm{~m}, \mathrm{Y} 12$, and G98). In this graph, the wind speed applied in the R11 function is the value plotted on the abscissa multiplied by 2.9. This adjustment corresponds to the lowest installation of the hotplate at OWL and decreases to 2.0 for measurements made after $17 \mathrm{De}-$ cember $201^{2}$. In our calculation of the R11 catch efficiency functions, the snow depth for the interval of interest (11 December 2013 to 29 January 2014) was set equal to the average $(0.7 \mathrm{~m})$ derived using an ultrasonic snow depth instrument operated at OWL (Campbell et al., 2016). This average and the AGL altitudes of the hotplate installation (Table 2) were used to derive the two wind-speed adjustment factors (2.9 and 2.0). The basis for this calculation is G98's gauge-height correction formula (their Eq. 4.3.1).

Since the anemometer at OWL was operated at nearly the same height as the top of the NOAH-II gauge (Steenburgh et al., 2014) and the G98 catch efficiency formula (their Eq. 4.7.1) assumes speeds are measured at the height of the gauge opening, a vertical adjustment of the wind speed was not factored into the G98 catch efficiencies.

\section{$4 \quad$ Testing and calibration results}

\subsection{Warm-cold tests}

Results from the warm-cold tests are described here. The derived $T_{\mathrm{h}} / \gamma$ pairs (Sect. 3.6) are in Table 3. The $T_{\mathrm{h}}$ values are $42.2{ }^{\circ} \mathrm{C}$ for the NCAR hotplate deployed at BTL (NCAR/BTL), $52.2^{\circ} \mathrm{C}$ the UW hotplate deployed at GLE (UW/GLE), and $65.5^{\circ} \mathrm{C}$ for the UW gauge deployed at OWL (UW/OWL). The first two $T_{\mathrm{h}} \mathrm{s}$ differ from those presented in Wettlaufer (2013) where, for the NCAR hotplate, he reported

\footnotetext{
2a.g.l. altitudes of the two hotplate installations are provided in Table 2 .
}

agreement with the nominal plate temperature $\left(75^{\circ} \mathrm{C} ; \mathrm{R} 11\right)$ and for the UW hotplate (GLE) he reported a larger temperature $\left(T_{\mathrm{h}}=109^{\circ} \mathrm{C}\right)$. The $T_{\mathrm{h}} / \gamma$ pair reported in Table 3 for the UW/OWL study was evaluated after Wettlaufer (2013) reported his warm-cold test results.

In our analysis of the warm-cold measurements we only used data acquired in the hangar. As we describe below, this may have improved the accuracy of the resultant $T_{\mathrm{h}} / \gamma$ pairs. This is because all data needed to derive a $T_{\mathrm{h}} / \gamma$ pair can be obtained without turning off the hotplate. Wettlaufer (2013) analyzed both hanger and lab data. Both in his work and in ours, the relevant hotplate properties were derived by averaging over a $5 \mathrm{~min}$ warm interval and a $5 \mathrm{~min}$ cold interval and applying these averages in Eqs. (7a)-(7b). For us the warm-cold temperature pairings are $5.4 /-4.3^{\circ} \mathrm{C}$ (NCAR/BTL), $7.0 /-1.1{ }^{\circ} \mathrm{C}$ (UW/GLE), and $29.5 / 10.4^{\circ} \mathrm{C}$ (UW/OWL). Compared with Wettlaufer (2013), our $T_{\mathrm{w}} \mathrm{s}$ are $15^{\circ} \mathrm{C}$ colder (NCAR/BTL and UW/GLE experiments only). Using our $T_{\mathrm{h}} / \gamma$ pairs (Table 3 ) and the first two $T_{\mathrm{w}}$ s (i.e., for NCAR/BTL and UW/GLE), we evaluated the term in Eq. (7a) representing natural-convective transfer $\left(D_{\mathrm{h}} \cdot K_{x}\right.$. $\left.\left(T_{\mathrm{h}}-T_{\mathrm{w}}\right) \cdot \gamma\right)$ and compared them with values derived using $T_{\mathrm{h}} / \gamma$ pairs in Wettlaufer (2013; his Table 2). In the NCAR/BTL comparison $T_{\mathrm{w}}$ was set at $5.4^{\circ} \mathrm{C}$ and in the UW/GLE comparison $T_{\mathrm{w}}$ was set at $7.0^{\circ} \mathrm{C}$. Our naturalconvective term agrees within $\pm 0.1 \mathrm{~W}$ of those derived by Wettlaufer (2013). Also in good agreement is the product of $T_{\mathrm{h}}$ and $\gamma$. Relative to Wettlaufer (2013), our $T_{\mathrm{h}} \cdot \gamma$ product is $6 \%$ larger (NCAR/BTL), and $7 \%$ larger (UW/GLE). We expect that our $T_{\mathrm{h}} / \gamma$ pairs (Table 3), when applied in Eq. (3), will produce a reasonable estimate of the precipitation rate. We test that expectation in the next section.

Error limits on $T_{\mathrm{h}}$ and $\gamma$ in Table 3 were derived by perturbing $Q_{\text {top,w }}$ (i.e., the value acquired in the warm test) by $\pm 0.5 \mathrm{~W}$ and repeating the analysis (Eqs. $7 \mathrm{a}-7 \mathrm{~b}$ ). Our estimate of the $Q_{\mathrm{top}, \mathrm{w}}$ error $( \pm 0.5 \mathrm{~W})$ came from a comparison of values acquired before and after power to the hotplate was stopped and restarted. These tests were conducted in the hangar and the 10 min warm-up recommended by the manufacturer was adhered to (YES, 2011).

\subsection{Drip tests}

This section compares two time sequences of precipitation rate: one is calculated with the new algorithm; the other is the hotplate-derived value (Table 1). The basis for the comparison is the measurements of artificially produced liquid precipitation made in the hangar. We applied water drops to the NCAR and UW hotplates using a volumetric water pump (Ismatec Inc.; Model 7618). Each of these tests has a drip period (4 min) and a nondrip period (5 min). Drops (4 $\mathrm{mm}$ volume-equivalent diameter) were added uniformly to the top plate at a constant volumetric rate. We convert the pump rate to a reference precipitation rate $\left(P_{\mathrm{REF}}\right)$ and apply 


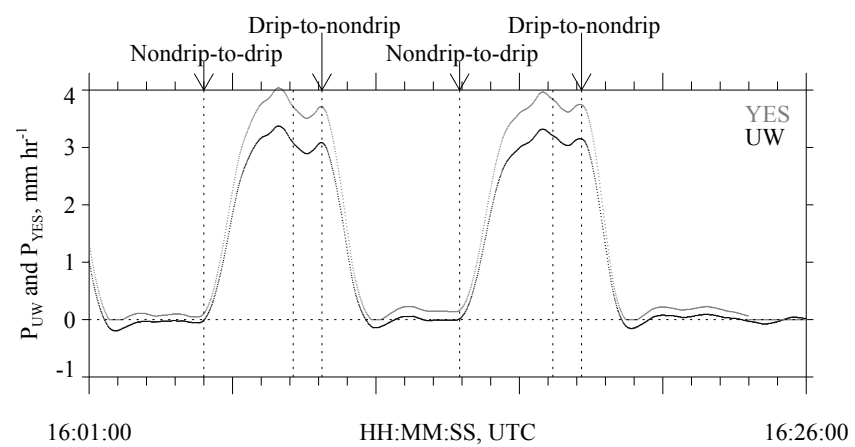

Figure 4. Precipitation rates, derived using the UW and YES algorithms, plotted against time. Dashed vertical lines illustrate nondripto-drip transitions, drip-to-nondrip transitions, and $1 \mathrm{~min}$ precipitation averaging intervals. In this figure, the $1 \mathrm{~min}$ averaging intervals are $\sim 16: 08$ to $\sim 16: 09$ UTC and $\sim 16: 17$ to $\sim 16: 18$ UTC. Measurements are from the UW hotplate operating indoors on 29 February 2012. The UW/GLE calibration constants (Table 3 ) and an $f_{2}$ derived with the second of two methods (Sect. 3.8) were applied in the UW algorithm.

the $P_{\mathrm{REF}}$ in subsequent analyses ${ }^{3}$. These drip tests were conducted at $T>4^{\circ} \mathrm{C}$.

Because the drip tests were conducted with the hotplate operating as in Fig. 2, and unventilated, the recorded data were analyzed with $T_{\mathrm{s}}=T$, in Eq. (6) (Sect. 3.5), and with the sensible power output formulated as $D_{\mathrm{h}} \cdot K_{x} \cdot\left(T_{\mathrm{h}}-T\right) \cdot \gamma$ (Appendix and Table 3). Also, because all of the pumped water is delivered to the top plate, the catch efficiency is $E=1$. Hotplate precipitation rates were derived by inputting measurements $\left(Q_{\text {top }}, T, U\right.$, and $\left.\mathrm{SW}\right)$ and a calculated variable $\left(\mathrm{IR}_{\mathrm{d}}\right.$; Sect. 3.5) into Eq. (3) and solving for a precipitation rate sequence $(P(t))$. We symbolize this $P(t)$ as $P_{\mathrm{UW}}$ and refer to calculations leading to that sequence as the UW algorithm. Also, we refer to sequences obtained from the UHP file (Table 1) as $P_{\text {YES }}$ and refer to that calculation as the YES algorithm.

We now compare values of $P_{\mathrm{UW}}$ to synchronous values of

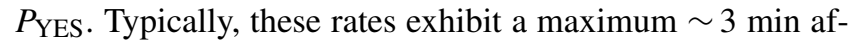
ter the nondrip-to-drip transition (Fig. 4). We interpret these maxima as overestimates, possibly due to a violation of the steady-state assumption. Also evident, particularly in the $P_{\text {UW }}$ sequence, is a minimum. This occurs during the time in which the instrument is relaxing to its rest state; i.e., $\sim 2 \mathrm{~min}$ after a drip-to-nondrip transition. The figure also demonstrates that thresholding is applied to the $P_{\text {YES }}$ sequence; i.e., the YES algorithm thresholds the output to $0 \mathrm{~mm} \mathrm{~h}^{-1}$ if values decrease to $<0 \mathrm{~mm} \mathrm{~h}^{-1}$. This is evident at $\sim 16: 11 \mathrm{UTC}$ and at three other times in the $P_{\text {YES }}$ sequence. In fact, thresholding is not desired for the drip tests. Thus, the UW sequence is not thresholded in Fig. 4.

\footnotetext{
${ }^{3}$ The value of the multiplier that converts the volumetric pump rate $\left(\mathrm{cm}^{3} \mathrm{~min}^{-1}\right)$ to precipitation rate $\left(\mathrm{mm} \mathrm{h}^{-1}\right)$ is 4.51 .
}

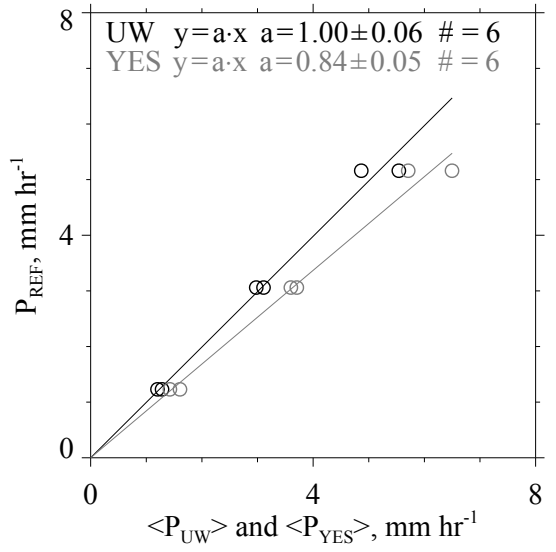

Figure 5. Reference precipitation rate vs. time-averaged $P_{\mathrm{UW}}$ and $P_{\text {YES. Measurements are from the UW hotplate operating indoors }}$ on 29 February 2012. The UW/GLE calibration constants (Table 3) and an $f_{2}$ derived with the second of two methods (Sect. 3.8) were applied in the UW algorithm. Regression lines were forced through the origin and $x$ deviations (horizontal departures of data from regression line) were used as the basis for the least squares criterion of best fit (Young, 1962). Standard deviations on the fitted ratios (confidence intervals) were derived using Student's $t$ distribution at the $95 \%$ level (Havilcek and Crain, 1988).

Two 1 min averaging intervals are shown in Fig. 4. We set the end of these at the drip-to-nondrip transitions and symbolize the averages as $\left\langle P_{\mathrm{UW}}\right\rangle$ and $\left\langle P_{\mathrm{YES}}\right\rangle$. Figure 5 is a compilation of the two tests already discussed plus four additional $P_{\mathrm{REF}}$ vs. $<P_{\mathrm{UW}}>$ comparisons and four additional $P_{\mathrm{REF}}$ vs. $<P_{\mathrm{YES}}>$ comparisons.

We now use a linear least squares regression analysis and a regression equation of the form $y=a \cdot x$ to derive the ratio of two precipitation rates. In Fig. 5 it is apparent that the regression slope (ratio) derived for the $P_{\mathrm{REF}}$ vs. $<P_{\mathrm{UW}}>$ comparison does not differ from one by more than \pm 1 standard deviation. Ratios for the two hotplates (UW and NCAR) and for three drip tests are summarized in Table 4. In the third column ( $P_{\mathrm{REF}}$ vs. $<P_{\mathrm{UW}}>$ ), we see that none of the ratios differ from one by more than \pm 1 standard deviation. In contrast to Fig. 5 and Table 4, we also evaluated intercepts of regressions that were not forced through the origin; none of these differ significantly from zero (results not shown). From the statistical comparisons in Table 4, we conclude that the $T_{\mathrm{h}} / \gamma$ pairs (Table 3) applied in the UW algorithm (Eq. 3) produce a precipitation rate consistent with the reference.

Values of the reference rate and the hotplate-derived rate $\left(<P_{\text {YES }}>\right)$ are compared as ratios in Fig. 5 and in the fourth column of Table 4 . These ratios are seen to deviate systematically from unity and in the direction discussed in Sect. 3.8. In the unforced regressions (not shown) the intercepts are negative, but only one of these differed significantly from zero (NCAR/BTL; intercept $=-0.3 \pm 0.1)$. Negative intercepts are expected because $P_{\mathrm{YES}}$ is positively offset, 


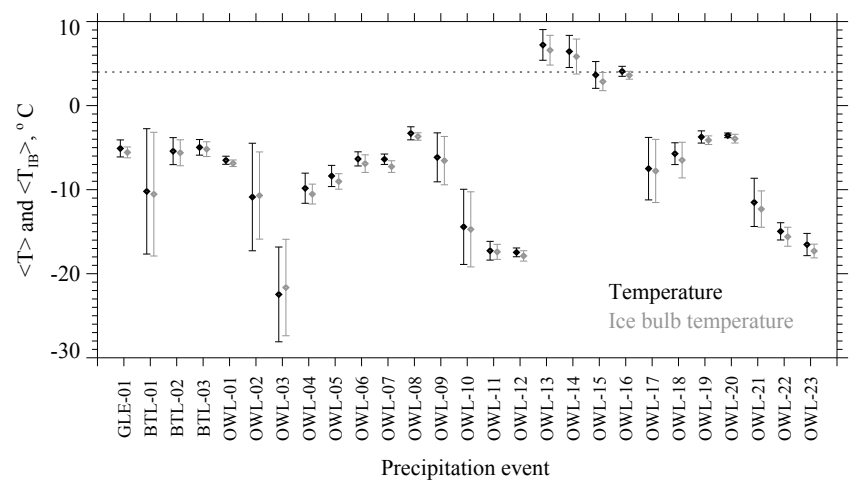

Figure 6. Event-averaged ambient temperature $(<T>)$ and eventaveraged ambient ice bulb temperature $\left.\left(<T_{\mathrm{IB}}\right\rangle\right)$. The abscissa shows the 27 precipitation events in the order presented in Table 5. Error bars are \pm 2 standard deviations. The dashed horizontal line is drawn at $+4{ }^{\circ} \mathrm{C}$.

by $\sim 0.2 \mathrm{~mm} \mathrm{~h}^{-1}$ during most of the nondrip periods (e.g., 16:21 UTC in Fig. 4).

\section{Field measurements}

This section is organized as follows: Sect. 5.1 presents field measurements of ambient temperature and ambient ice bulb temperature. We use this information to classify 27 precipitation events as either snowfall or rainfall. Section 5.2 presents the $N u-R e$ relationship we use to account for the sensible power output in Eq. (3). Section 5.3 describes how we derive a precipitation rate based on hotplate measurements made in the field. Section 5.4 compares time-integrated precipitation rates (accumulations) derived using the two algorithms. In Sect. 5.4, we also compare hotplate accumulations to values from the NOAH-II.

\subsection{Field-measured temperatures and ice bulb temperatures}

The 27 precipitation events are summarized in Table 5. Measurements were made during 2012, at the two southeastern Wyoming field sites (BTL and GLE), and during 2013 and 2014 at the western New York site (OWL). Table 5 and Fig. 6 have event-averaged ambient temperatures $(<T>)$ and event-averaged ambient ice bulb temperatures $\left(<T_{\mathrm{IB}}>\right)$. Twenty-three of the events have $<T>\leq-3.3^{\circ} \mathrm{C}$ and upperlimit temperature $(<T>$ plus two standard deviations) no warmer than $-2.3^{\circ} \mathrm{C}$. We classified these as snowfall. In addition, we classified four events as rainfall. These had $<T_{\mathrm{IB}}>\geq+2.9^{\circ} \mathrm{C}$ and a lower-limit temperature $(<T>$ minus two standard deviations) no colder than $+2{ }^{\circ} \mathrm{C}$.

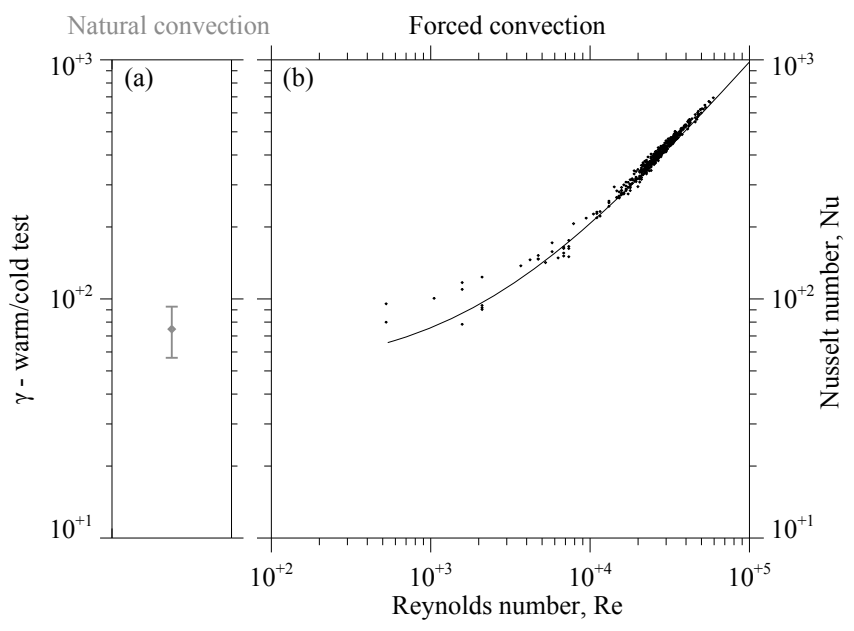

Figure 7. (a) $\gamma$ from the warm-cold test summarized in the second row of Table 3. Error limits were derived by perturbing $Q_{\text {top,w }}$ (i.e., the value acquired in the warm test) by $\pm 0.5 \mathrm{~W}$ and repeating the analysis based on Eqs. (7a)-(7b). (b) $N u$ vs. Re scatter plot and fit curve for the UW hotplate at the GLE site. For clarity, only every fortieth $N u-R e$ data pair is plotted. The minimum $R e$ plotted (data and fit function) corresponds to the minimum $U$ reported in the UHP file $\left(0.1 \mathrm{~m} \mathrm{~s}^{-1}\right)$. The measurement interval is 2 April 2012, 04:00 UTC to 2 April 2012, 09:00 UTC at the GLE site. The UW/GLE $T_{\mathrm{h}}$ (Table 3 ) was applied in the data analysis.

\subsection{Nusselt-Reynolds relationship}

Figure $7 \mathrm{~b}$ shows a plot of the $N u-R e$ fit function with the data used to constrain the function. This result is based on UW hotplate measurements (GLE site) and formulas developed in Sect. 3.7. Fit coefficients $(\alpha, \beta$, and $\gamma)$ are reported in Table 6 for each field site. Hansen and Webb (1992) reported $\alpha=0.09$ and $\beta$ between 0.69 and 0.72 for a surface similar to the hotplate (circular with three concentric rings); however, their flow direction was perpendicular to the plate surface. The values of $\alpha$ and $\beta$ we report may differ from those in Hansen and Webb (1992) because the flow is principally parallel to the plate surface at our field sites. There are two other differences relative to Hansen and Webb (1992): (1) our geometrically averaged $N u(\sim 360)$ is about a factor of 5 larger, and (2) our $R e$ extends over a much larger range. Finally, we note that compared to Fig. $7 \mathrm{~b}$ there is an order of magnitude narrower $R e$ range in the NCAR/BTL and UW/OWL $N u$ - Re plots (not shown).

Figure $7 \mathrm{a}$ is a companion to Fig. $7 \mathrm{~b}$ showing the $\gamma$ based on the warm-cold test. The error limit on this datum is explained in Sect. 4.1. Since $N u$ is dependent on the $T_{\mathrm{h}}$ derived in the warm-cold test (Sect. 3.6), we expect the $\mathrm{Nu}$-Re function to converge to the warm-cold $\gamma$ in the limit of small $R e$. In our assessment of convergence, we evaluated the limiting $N u$ at the $R e$ corresponding to the minimum $U$ reported in the hotplate data output $\left(0.1 \mathrm{~m} \mathrm{~s}^{-1}\right)$. This minimum $U$ establishes the left end of the function in Fig. 7b. Convergence 


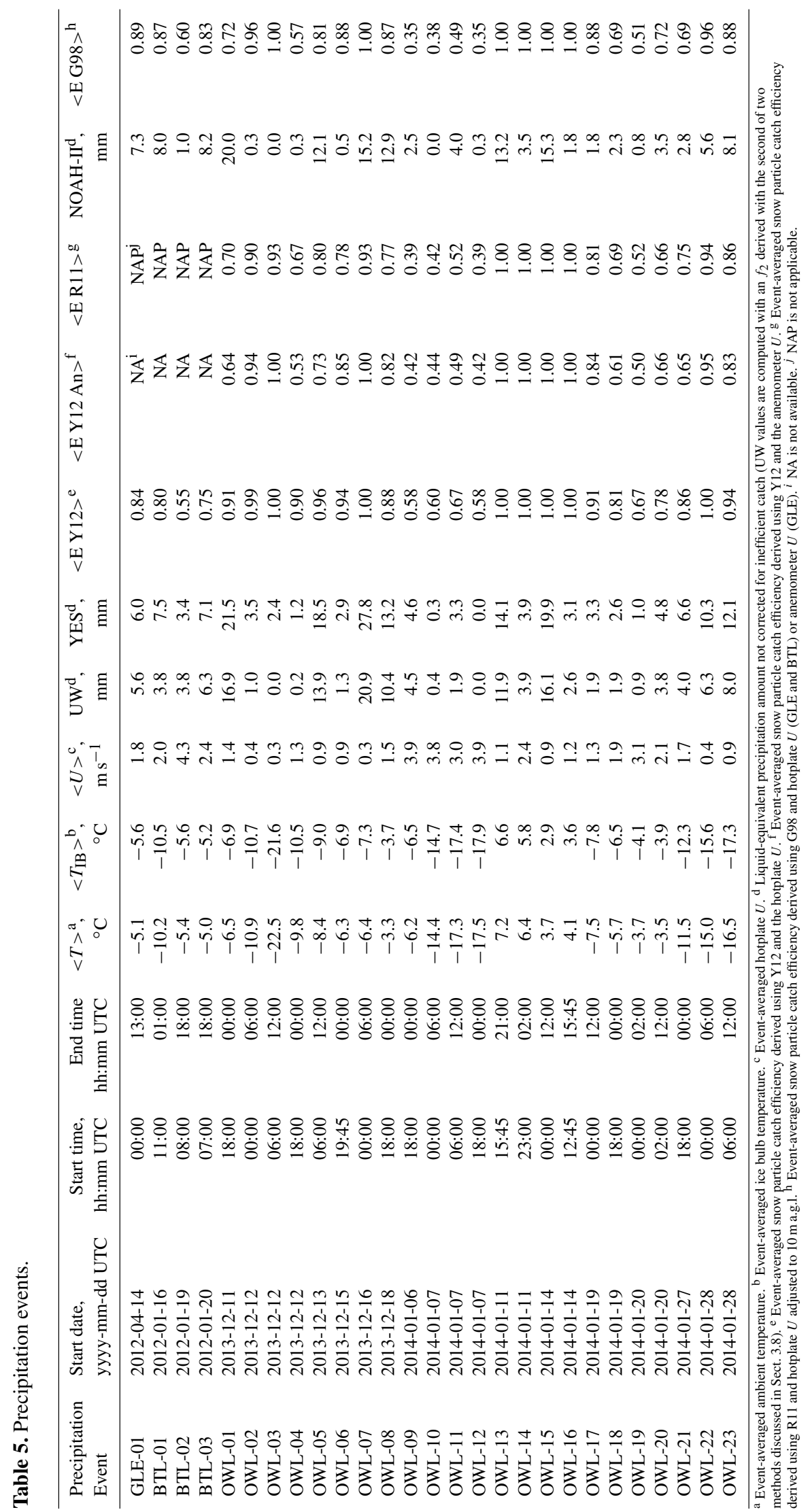


Table 6. Summary of fitted $N u-R e$ coefficients.

\begin{tabular}{lrrr}
\hline Field calibration & \multicolumn{3}{c}{$(N u-R e$ coefficients $)$} \\
\hline Hotplate/field site & $\gamma$ & $\alpha$ & $\beta$ \\
\hline NCAR/BTL $^{\mathrm{a}}$ & 86.2 & 0.126 & 0.781 \\
UW/GLE $^{\mathrm{b}}$ & 49.1 & 0.130 & 0.771 \\
$\mathrm{UW}^{\mathrm{O} O W L}$ & 45.6 & 0.172 & 0.713
\end{tabular}

a NCAR hotplate; measurement interval 18 January 2012,

23:00 UTC to 19 January 2012, 05:00 UTC. ${ }^{\text {b }}$ UW hotplate;

measurement interval 2 April 2012, 04:00 UTC to

2 April 2012, 09:00 UTC. ${ }^{\mathrm{c}}$ UW hotplate; measurement

interval 7 January 2014, 18:00 UTC to 8 January 2014,

08:00 UTC.

of the $N u-R e$ relationship to within the error limit on the warm-cold $\gamma$, at the former's left-most limit, is evident in Fig. 7a-b. Convergence is also evident in the NCAR/BTL and UW/OWL plots analogous to Fig. 7a-b (not shown) and this in spite of narrower $R e$ range in those data sets.

\subsection{Precipitation rate from field measurements}

Figure 8 shows budget terms (Eq. 3) for one of the four rainfall events in our data set (OWL-15). The three output terms (sensible, latent, and longwave) and three input terms (top plate, longwave, and shortwave) are shown in Fig. 8ab. In this section we begin with the latent power output (i.e., $P \cdot E / f_{2}$ in Fig. 8a) and describe how we calculate the rainfall rate. We also contrast that calculation with steps followed in the case of snowfall.

The first step in the calculation is the conversion of the latent power output term (Fig. 8a) to a provisional precipitation rate; this is done by multiplying each element of the term by the corresponding element of $f_{2}$ (Eq. 9b). This operation is referred to as element-by-element vector multiplication. Thresholding is applied next. Both a $300 \mathrm{~s}$ running average of the provisional rate and a $10 \mathrm{~s}$ running average of the provisional rate are computed. If the $300 \mathrm{~s}$ average exceeds $0.25 \mathrm{~mm} \mathrm{~h}^{-1}$ and the $10 \mathrm{~s}$ average exceeds $0 \mathrm{~mm} \mathrm{~h}^{-1}$, the rate is stored as the $10 \mathrm{~s}$ average; otherwise the rate is stored as $0 \mathrm{~mm} \mathrm{~h}^{-1}$. We refer to the resultant as $P_{\mathrm{UW}}$, but we note that in Sect. 4.2 the $P_{\text {Uw }}$ sequences are unthresholded. Both the thresholded and unthresholded sequences are presented in Fig. 8c-d. The thresholded $P_{\mathrm{UW}}$ is identical to the unthresholded $P_{\mathrm{UW}}$ where the $300 \mathrm{~s}$ average exceeds $0.25 \mathrm{~mm} \mathrm{~h}^{-1}$ and the $10 \mathrm{~s}$ average exceeds $0 \mathrm{~mm} \mathrm{~h}^{-1}$.

In the case of snowfall, the $f_{2}$ is calculated using Eq. (9a) and applied as discussed in the previous paragraph. Finally, the precipitation rate is derived as the resultant of element-by-element vector multiplication of the thresholded $P_{\mathrm{UW}}$ and the reciprocal of the snow particle catch efficiency (Sect. 3.9).

\subsection{Comparisons of liquid-equivalent accumulation}

Here we use linear least squares regression analysis with a regression equation of form $y=a \cdot x$ to derive the ratio of two measures of liquid-equivalent accumulation for snow. In Fig. 9, these measures are the accumulations derived using the UW and YES algorithms. In the these algorithms the particle catch efficiency function is the one described in Y12 and $f_{2}$ is $2.66 \cdot 10^{-8} \mathrm{~m} \mathrm{~J}^{-1}$ (Sect. 3.8). The data points correspond to measurements made at GLE (UW hotplate), at BTL (NCAR hotplate), and at OWL (UW hotplate). We note that 19 of 23 y axis values are from the same instrument (UW hotplate) and are derived using the same calibration (UW/OWL) used to produce the result shown in the third row of Table 4. Statistical consistency between the ratio in Fig. 9 $(0.79 \pm 0.05)$ and the ratio in the third row of Table 4 (i.e., $0.79 \pm 0.03$ for the $P_{\mathrm{REF}}$ on $\left\langle P_{\mathrm{YES}}>\right.$ ratio) suggest a systematic error in the YES-derived precipitation rates and accumulations. This assertion is reinforced by the three NCAR hotplate points straddling the best-fit line in Fig. 9 and by the ratio reported in Table 4 for the NCAR hotplate (i.e., $0.81 \pm 0.03$ for the $P_{\mathrm{REF}}$ on $\left\langle P_{\mathrm{YES}}>\right.$ ratio). However, we cannot exclude the possibility that bias in our field-based calibration coefficients $(\alpha, \beta$, and $\gamma$; Table 6$)$ is the reason for a UW / YES ratio significantly smaller than unity in Fig. 9.

As was discussed in Sect. 4.2 and demonstrated in Fig. 4, during the indoor nondrip periods the $P_{\mathrm{YES}}$ sequence is positively offset. A plausible reason for this, and for the ratios $<1$ reported in the previous paragraph, is disregard of longwave forcing in the YES algorithm. Since we do not have access to the YES algorithm, we estimated the longwave radiative effect by setting the longwave terms to zero in Eq. (3). After doing this, a larger UW / YES ratio $(a=0.83 \pm 0.04)$ was obtained in a plot analogous to Fig. 9. From this modest increase of the UW / YES ratio, we conclude that longwave forcing cannot explain the shift of the best-fit line away from unity in Fig. 9. An even smaller perturbation of the UW / YES ratio was obtained in calculations that set the shortwave term to zero in Eq. (3) (results not shown).

Further evidence for systematic error in the YES values comes from Fig. 10. With the exception that these data are observed for rain at OWL (Sect. 5.1), the comparison in Fig. 10 is similar to Fig. 9. Although the number of points is small, Fig. 10 establishes that our finding of a UW / YES ratio significantly smaller than unity is true for both rainfall and snowfall. In addition, Fig. 11 strengthens this conclusion by showing agreement between values of the UW accumulation and the NOAH-II accumulation when both gauges detected rain.

An additional assessment of snowfall at OWL is presented in Fig. 12a-c. In these graphs the NOAH-II measurements are plotted on the abscissa and different interpretations of the UW hotplate measurements are plotted on the ordinate. For both devices, we plot the ratio of a liquid-equivalent accumulation divided by an event-averaged catch efficiency, and 


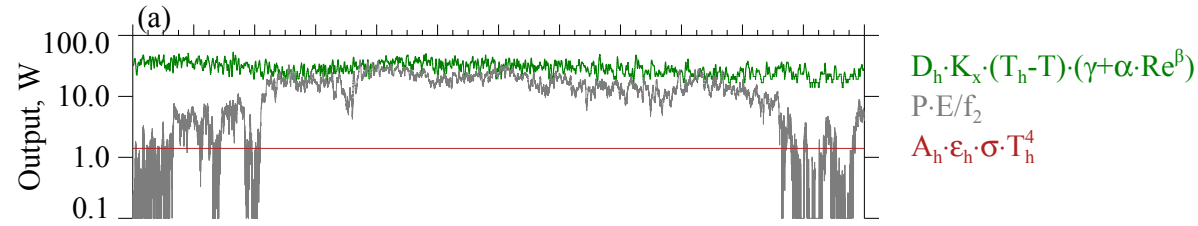

(b)
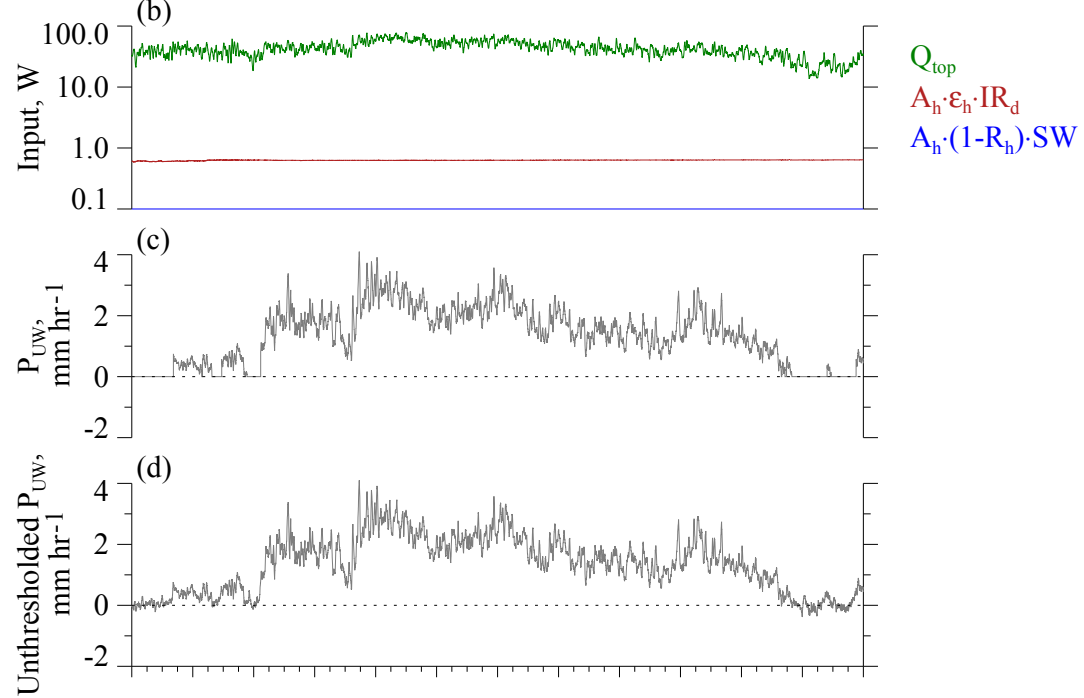

00:00:00 HH:MM:SS, UTC 12:00:00

Figure 8. Hotplate properties during rain (event $=$ OWL-15). Because this event classifies as rain, $E=1$ was applied in the analysis. (a) Budget output terms (Eq. 3), i.e., the sensible, latent, and longwave outputs. (b) Budget input terms (Eq. 3), i.e., top plate, longwave, and shortwave inputs. The shortwave term is zero for this nighttime example but is set to $0.1 \mathrm{~W}$ in the plot. (c) Thresholded precipitation rate. (d) Unthresholded precipitation rate.

we note that the numerators of these ratios are accumulations that were not corrected for inefficient catch $^{4}$. Table 5 demonstrates two features of the OWL snow data set: (1) the event-averaged catch efficiency based on Y12 ( $<$ E Y12 $>)$ is consistently larger than the event-averaged efficiency based on R11 ( $<\mathrm{E} \mathrm{R} 11>$ ), and (2) the event-averaged efficiency $<$ E R11 $>$ is comparable to $<$ E Y12 An $>$, where the latter is the event-averaged efficiency derived with the anemometer $U$ and the Y12 catch efficiency function. These features are consistent with the altitude adjustment in R11, which increases the wind speed (Sect. 3.9) and thus decreases $<\mathrm{E}$ $\mathrm{R} 11>$ relative to $<\mathrm{E}$ Y12 $>$. They are also consistent with a low bias in the hotplate-derived $U$. The latter is supported by a comparison of the hotplate $U$ vs. anemometer $U$ where the fit-line slope is $0.55 \pm 0.05$ for the 19 snow events at OWL (results not shown).

Consistent with the ranking of event-averaged values of $E$ (Table 5), Fig. 12a shows that the hotplate values, derived with the hotplate $U$ and the Y12 catch efficiency function, are smaller (on average) than the NOAH-II-derived values. We also see that the $15 \%$ underestimate in the hotplate (Fig. 12a)

\footnotetext{
${ }^{4}$ This comparison was also made using accumulations corrected with a time-dependent catch efficiency (Sect. 5.3), but we found that the fit-line slopes differed by less than $\pm 5 \%$ from those in Fig. 12.
}

reverses to a slight overestimate when using the R11 catch efficiency function (Fig. 12b) and when using the anemometer $U$ with the Y12 function (Fig. 12c). These results do not allow us to specify contributions to the $15 \%$ underestimate (Fig. 12a), coming from the fact that the Y12 function does not use a height-adjusted $U$, or from the suspected hotplate underestimate of $U$. Further studies that focus on the development of a hotplate catch efficiency function that is dependent on the local wind speed as opposed to the wind speed at $10 \mathrm{~m} \mathrm{(R11)} \mathrm{and} \mathrm{an} \mathrm{investigation} \mathrm{of} \mathrm{the} \mathrm{hotplate's} \mathrm{determi-}$ nation of wind speed are needed to resolve this issue. Since there is error in the NOAH-II values used in this comparison, there is also a need for characterization of that uncertainty. The latter can propagate from the NOAH-II measurements themselves and from the catch efficiency function we applied to those data (Sect. 3.9).

\section{Conclusions}

Starting with measurements acquired from two YES hotplates, we derived precipitation rates and accumulations for 27 snowfall and rainfall events. The basis for this is a power budget equation similar to that in King et al. (1978). We changed the budget equation by including terms describing 


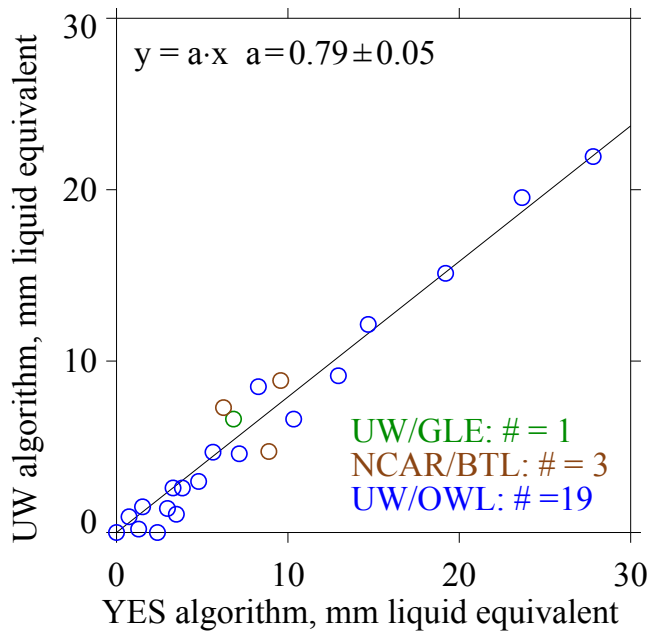

Figure 9. Snow accumulations derived using the UW algorithm vs. snow accumulations derived using the YES algorithm. Both the Y12 catch efficiency function and an $f_{2}$ derived with the first of two methods discussed in Sect. 3.8 were applied in the UW algorithm. The regression line was forced through the origin and $y$ deviations (vertical departures of data from regression line) were used as the basis for the least squares criterion of best fit (Young, 1962). The standard deviation on the fitted ratio (confidence interval) was derived using Student's $t$ distribution at the $95 \%$ level (Havilcek and Crain, 1988).

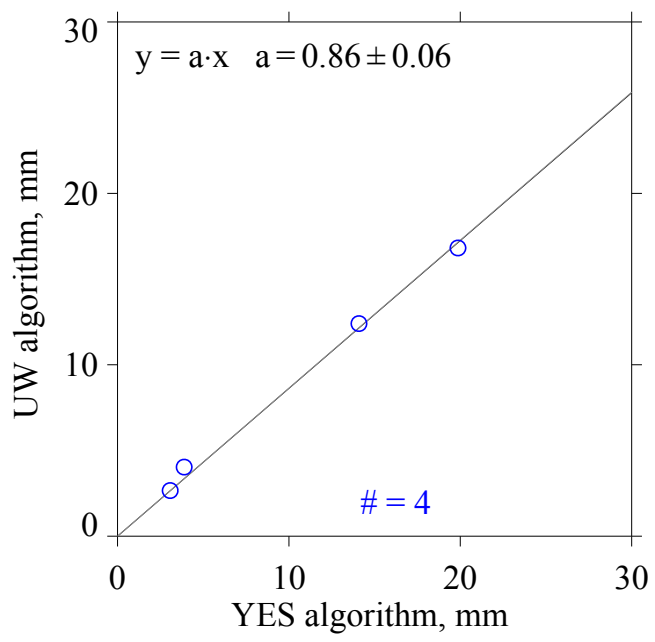

Figure 10. Rain accumulations derived using the UW algorithm vs. rain accumulations derived using the YES algorithm. An $f_{2}$ derived with the first of two methods discussed in Sect. 3.8 was applied in the UW algorithm. The regression line was forced through the origin and $y$ deviations (vertical departures of data from regression line) were used as the basis for the least squares criterion of best fit (Young, 1962). The standard deviation on the fitted ratio (confidence intervals) was derived using Student's $t$ distribution at the $95 \%$ level (Havilcek and Crain, 1988).

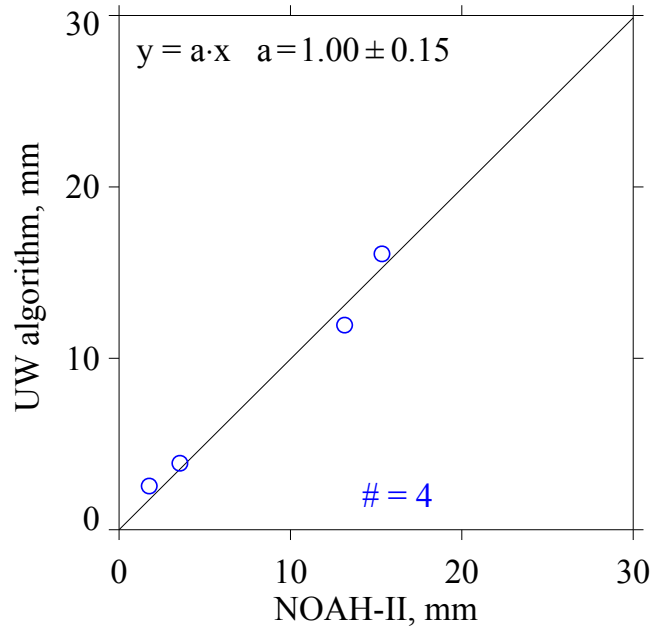

Figure 11. Rain accumulations derived using the UW algorithm vs. rain accumulations from the NOAH-II gauge. An $f_{2}$ derived with the second of two methods discussed in Sect. 3.8 was applied in the UW algorithm. The regression line was forced through the origin and $y$ deviations (vertical departures of data from regression line) were used as the basis for the least squares criterion of best fit (Young, 1962). The standard deviation on the fitted ratio (confidence intervals) was derived using Student's $t$ distribution at the $95 \%$ level (Havilcek and Crain, 1988).

the longwave and shortwave radiant energy transfers. To the best of our knowledge, this is the first time that radiative terms have been incorporated into a hotplate data analysis algorithm and reported in the scientific literature.

We demonstrated that radiative forcing of the budget is relatively unimportant for the precipitation events analyzed. This is because the top plate's shortwave absorptance (i.e., 1 $-R_{\mathrm{h}}$ in Eq. 3) and its longwave emissivity are small compared to unity, because a majority of events occurred at night and because generally overcast conditions diminished the significance of the longwave forcing.

In this paper, we used computational methods different from those in R11, and we derived and applied different calibration coefficients. In spite of these changes we report precipitation rates and accumulations that strongly correlate with the output of two YES hotplates. However, a systematic difference is evident in our comparisons of the UW and YES algorithms. We surmise that the difference comes from the following: (1) R11's assignment of $A_{\mathrm{h}}\left(0.00884 \mathrm{~m}^{2}\right.$ vs. $0.01327 \mathrm{~m}^{2}$ in the UW algorithm), (2) R11's distinction between a theoretical and an actual energy conversion factor, and (3) the incorporation of points 1 and 2 into the YES algorithm. Clearly, R11's $A_{\mathrm{h}}$ is not justified for hotplates sold by YES (Boudala et al., 2014; YES, personal communication, 2017). R11's distinction between conversion factors is more problematic. That distinction can be interpreted two ways: either (1) the distinction accounts for environmental thermal energy input that assists the conversion of precipitation mass 

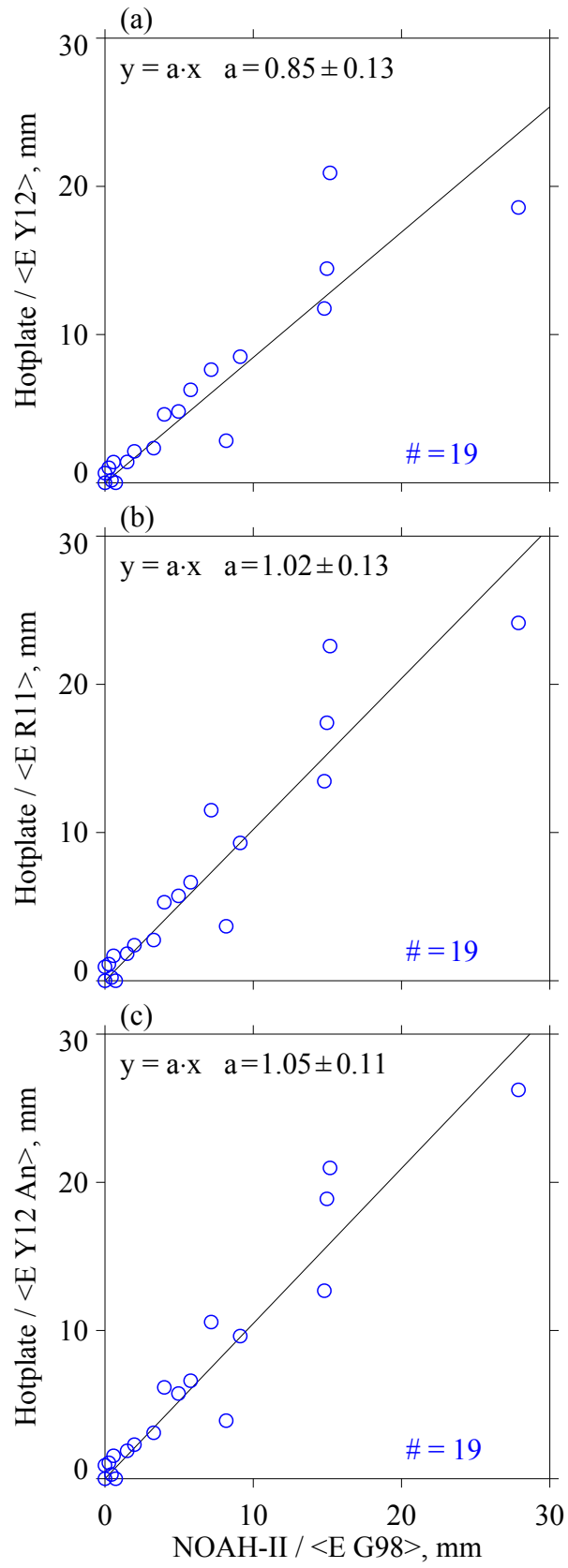

Figure 12. UW hotplate and NOAH-II measurements of snow (liquid-equivalent accumulations, not corrected for inefficient catch, divided by an event-averaged snow particle catch efficiency) at OWL. An $f_{2}$ derived with the second of two methods discussed in Sect. 3.8 was applied in the UW algorithm. Regression lines were forced through the origin and $y$ deviations (vertical departures of data from regression line) were used as the basis for the least squares criterion of best fit (Young, 1962). The standard deviations on the fitted ratios (confidence intervals) were derived using Student's $t$ distribution at the $95 \%$ level (Havilcek and Crain, 1988). to vapor, or (2) the distinction accounts for the loss of snow particles from the top surface of the hotplate due to removal by wind. Because early in the warming process a precipitation element attains a temperature larger than that of the air, we assert that the first of these phenomena is unlikely to contribute significantly to the energy budget. The second may be significant, but it is our opinion that the removal of precipitation mass by wind is best accounted for with a catch efficiency, not with a distinction between conversion factors. Lastly, accounting for either of these phenomena, independent of an adjustment of the catch efficiency, should be accomplished with an increase of an actual conversion factor relative to the theoretical value, not with the decrease proposed by R11.

Data availability. Data sets used in this analysis can be accessed at Steenburgh et al. (2014), at Wettlaufer and Snider (2015) and at https://doi.org/10.15786/M2JT13. Because the SHP files discussed in Sect. 2.1 are proprietary, those data are not provided. 


\section{Appendix A: Nomenclature}

$A_{\mathrm{h}} \quad$ Area of YES hotplate $=0.01327 \mathrm{~m}^{2}$

$C$ Liquid $\mathrm{H}_{2} \mathrm{O}$ specific heat capacity = $4218 \mathrm{~J} \mathrm{~kg}^{-1} \mathrm{~K}^{-1} \quad$ (assumed independent of temperature; Iribarne and Godson, 1981; their Table IV-5)

$C_{i} \quad$ Solid $\mathrm{H}_{2} \mathrm{O}$ specific heat capacity $=$ $2106 \mathrm{~J} \mathrm{~kg}^{-1} \mathrm{~K}^{-1} \quad$ (assumed independent of temperature; Iribarne and Godson, 1981; their Table IV-5)

$D_{\mathrm{h}} \quad$ Diameter of YES hotplate $=0.130 \mathrm{~m}$

$E \quad$ Snow particle catch efficiency (Sect. 3.9)

$f_{1} \quad$ Wind-speed-dependent property in Eq. (2) [W]

$f_{2} \quad$ Electrical-to-precipitation conversion factor $\left[\mathrm{m} \mathrm{J}^{-1}\right.$ ]

IR Upwelling or downwelling component of longwave flux [ $\mathrm{W} \mathrm{m}^{-2}$ ]

$L_{\mathrm{f}}\left(T_{o}\right) \quad$ Latent heat of fusion evaluated at the thermodynamic reference temperature $=0.3337$. $10^{6} \mathrm{~J} \mathrm{~kg}^{-1}$ (Iribarne and Godson, 1981; their Table IV-5)

$L_{\mathrm{v}}\left(T_{\mathrm{h}}\right) \quad$ Latent heat of vaporization at $T_{\mathrm{h}}$ (Iribarne and Godson, 1981; their Eq. 4.103) [ $\mathrm{J} \mathrm{kg}^{-1}$ ]

$M_{\mathrm{IR}} \quad$ Measured longwave flux (Sect. 3.5) $\left[\mathrm{W} \mathrm{m}^{-2}\right]$

$\mathrm{Nu} \quad$ Nusselt number

$P \quad$ Liquid-equivalent precipitation rate $\left[\mathrm{mm} \mathrm{h}^{-1}\right.$ or $\mathrm{m}^{3} \mathrm{~m}^{-2} \mathrm{~s}^{-1}$ ]

$P_{\text {Ref }} \quad$ Reference precipitation rate (Sect. 4.2) $\left[\mathrm{mm} \mathrm{h}^{-1}\right.$ or $\mathrm{m}^{3} \mathrm{~m}^{-2} \mathrm{~s}^{-1}$ ]

$P_{\text {UW }} \quad$ Precipitation rate derived with UW algorithm (Sect. 4.2 and 5.3) $\left[\mathrm{mm} \mathrm{h}^{-1}\right.$ or $\mathrm{m}^{3} \mathrm{~m}^{-2} \mathrm{~s}^{-1}$ ]

$P_{\text {YES }} \quad$ Precipitation rate derived with YES algorithm (Sect. 4.2) $\left[\mathrm{mm} \mathrm{h}^{-1}\right.$ or $\left.\mathrm{m}^{3} \mathrm{~m}^{-2} \mathrm{~s}^{-1}\right]$

$Q_{\text {bot }} \quad$ Bottom plate power [W]

$Q_{\text {top }} \quad$ Top plate power [W]

$R_{\mathrm{d}}$ Dry-air specific gas constant = $287 \mathrm{~J} \mathrm{~kg}^{-1} \mathrm{~K}^{-1}$

Re Reynolds number

$R_{\mathrm{h}} \quad$ Hotplate reflectance $=0.63$ (Sect. 2.2)

SW Measured shortwave flux (Sect. 2.2) [ $\left[\mathrm{W} \mathrm{m}^{-2}\right]$

$T \quad$ Ambient temperature $\left[{ }^{\circ} \mathrm{C}\right.$ or $\left.\mathrm{K}\right]$

$T_{\mathrm{h}} \quad$ Hotplate surface temperature (Sect. 3.6) $\left[{ }^{\circ} \mathrm{C}\right.$ or $\mathrm{K}]$

$T_{o} \quad$ Thermodynamic reference temperature $=$ $0.0^{\circ} \mathrm{C}$

$T_{\mathrm{S}} \quad$ Temperature of painted-steel sheeting $\left[{ }^{\circ} \mathrm{C}\right.$ or $\mathrm{K}]$

$U \quad$ Wind speed $\left[\mathrm{m} \mathrm{s}^{-1}\right]$

\section{Greek symbols}

$\alpha \quad$ Fitted $N u-R e$ coefficient (Sect. 3.7)

$\beta \quad$ Fitted $N u-R e$ coefficient (Sect. 3.7)

$\varepsilon_{\mathrm{h}} \quad$ Hotplate emissivity $=0.14$ (Sect. 2.2)

$\varepsilon_{\mathrm{s}} \quad$ Emissivity of painted-steel sheeting $=0.84$ (Sect. 3.4)

$\gamma$ Coefficient derived in warm-cold tests (Sect. 3.6) or a coefficient in the $N u-R e$ relationship (Sect. 5.2)

$\rho \quad$ Liquid $\mathrm{H}_{2} \mathrm{O}$ density $=1000 \mathrm{~kg} \mathrm{~m}^{-3}$ (assumed independent of temperature)

$\sigma$ Stefan-Boltzmann constant $=5.67$ $10^{-8} \mathrm{~W} \mathrm{~m}^{-2} \mathrm{~K}^{-4}$

\section{Subscripts}

c Indoor cold setting

d Downwelling

h Hotplate

IB Ice bulb

s Painted-steel sheeting

u Upwelling

w Indoor warm setting

$x \quad$ Property of air film adjacent to the hotplate surface: $p_{x}=$ standard-atmosphere pressure at the altitude of the measurement. The following three film properties are held constant in calculation of the Reynolds number (Sect. 3.7) and in calculation of the sensible power output due to molecular conduction (Sect. 3.7): (1) temperature ( $T_{x}=$ $303.15 \mathrm{~K})$, (2) dynamic viscosity $\left(\mu_{x}=1.862\right.$. $10^{-5} \mathrm{~kg} \mathrm{~m}^{-1} \mathrm{~s}^{-1}$; Rogers and Yau, 1989; their Table 7.1), and (3) thermal conductivity $\left(K_{x}=2.63\right.$. $10^{-2} \mathrm{~J} \mathrm{~m}^{-1} \mathrm{~s}^{-1} \mathrm{~K}^{-1}$; Rogers and Yau, 1989; their Table 7.1).

\section{Operator}

$<y>$ Time average of property $y$ 
Competing interests. The authors declare that they have no conflict of interest.

Acknowledgements. We gratefully acknowledge the support provided by the UW Department of Atmospheric Science Engineering Group. We also thank Ontario Winter Lake-effect Systems (OWLeS) project PIs Bart Geerts, Dave Kristovich, and James Steenburgh for their leadership and Philip Bergmaier for maintaining the UW hotplate during OWLeS. Lastly, we thank John Kochendorfer, Christophe Genthon, and Roy Rasmussen for their numerous critiques and comments, all of which greatly improved the paper. This work was supported by the United States National Science Foundation (Award EPS 1208909), the Wyoming Water Development Commission (Award WWDC40395H), and by the U.S. Department of Interior (Award 1000628L).

Edited by: Dominique Ruffieux

Reviewed by: John Kochendorfer and Christophe Genthon

\section{References}

Albrecht, B., Poellot, M., and Cox, S. K.: Pyrgeometer measurements from aircraft, Rev. Sci. Instrum., 45, 33-38, 1974.

Borkhuu, B.: Snowfall at a high-elevation site: Comparisons of six measurement techniques, MS Thesis, Department of Atmospheric Science, University of Wyoming, 2009.

Boudala, F. S., Rasmussen, R., Isaac, G. A., and Scott, B.: Performance of hot plate for measureing solid precipitation in complex terrain during the 2010 Vancouver Winter Olympics, J. Atmos. Ocean. Tech., 31, 437-446, 2014.

Brandes, E. A., Ikeda, K., Zhang, G., Schonhuber, M., and Rasmussen, R. M.: A statistical and physical description of hydrometeor distributions in Colorado snowstorms using a video disdrometer, J. Appl. Meteorol. Clim., 46, 634-650, 2007.

Brock, F. V. and Richardson, S. J.: Meteorological Measurement Systems, Oxford University Press, New York, 304 pp., 2001.

Campbell, L. S., Steenburgh, W. J., Veals, P. G., Letcher, T. W., and Minder, J. R.: Lake-Effect Mode and Precipitation Enhancement over the Tug Hill Plateau during OWLeS IOP2b, Mon. Weather Rev., 144, 1729-1748, https://doi.org/10.1175/MWRD-15-0412.1, 2016.

Currie, I.: Snow in the rain gauge (photograph), Weather, 53, p. 100, 1989.

Deshler, T.: Corrections of surface particle probe measurements for the effects of aspiration, J. Atmos. Ocean. Tech., 5, 547-560, 1988.

Goodison, B. E., Louie, P. Y. T., and Yang, D.: WMO solid precipitation measurement intercomparison, WMO Tech. Doc. 872, 211 pp., 1998.

Hansen, L. G. and Webb, B. W.: Air jet impingement heat transfer from modified surfaces, Int. J. Heat Mass Tran., 36, 989-997, 1992.

Hass, G.: Filmed surfaces for reflecting optics, J. Opt. Soc. Am., 45, 945-952, 1955.

Havilcek, L. L. and Crain, R. D.: Practical Statistics for the Physical Sciences, American Chemical Society, 489 pp., 1988.
Iribarne, J. V. and Godson, W. L.: Atmospheric Thermodynamics, 2nd Edn., Reidel, 259 pp., 1981.

Jevons, W. S.: On the deficiency of rain in an elevated rain gauge as caused by wind, London Edinburgh Dublin, Philos. Mag., 22, 421-433, 1861

King, W. D., Parkin, D. A., and Handsworth, R. J.: A hot-wire liquid water device having fully calculable response characteristics, J. Appl. Meteorol., 17, 809-813, 1978.

Kobus, C. J. and Wedekind, G. L.: An experimental investigation into forced, natural and combined forced and natural convective heat transfer from stationary isothermal circular disks, Int. J. Heat Mass Tran., 38, 3329-3339, 1995.

Lempio, G. E., Bumke, K., and Macke, A.: Measurement of solid precipitation with an optical disdrometer, Adv. Geosci., 10, 9197, 2007.

Locatelli, J. D. and Hobbs, P. V.: Fall speeds and masses of solid precipitation particles, J. Geophys. Res., 79, 2185-2197, 1974.

Loffler-Mang, M. and Joss, J.: An optical disdrometer for measuring size and velocity of hydrometeors, J. Atmos. Ocean. Tech., 17, 130-139, 2000.

Lovblad, G., Erisman, J. W., and Fowler, D.: Deposition monitoring. Models and Methods for the Quantification of Atmospheric Input to Ecosystems, chap. 3, The Nordic Council of Ministers, 37-41, 1993.

Nespor, V. and Servuk, B.: Estimation of wind-induced error of rainfall gauge measurements using a numerical simulation, J. Atmos. Ocean. Tech., 16, 450-464, 1999.

Panofsky, H. A. and Dutton, J. A.: Atmospheric Turbulence, WileyInterscience, New York, 397 pp., 1984.

Rasmussen, R. M., Hallett, R., Purcell, J., Landolt, S. D., and Cole, J.: The hotplate precipitation gauge, J. Atmos. Ocean. Tech., 28, 148-164, 2011.

Rasmussen, R., Baker, B., Kochendorfer, J., Meyers, T., Landolt, S., Fischer, A. P., Black, J., Theriault, J. M., Kucera, P., Gochis, D., Smith, C., Nitu, R., Hall, M., Ikeda, K., and Gutmann, E.: How well are we measuring snow?, B. Am. Meteorol. Soc., 93, 811-829, 2012.

Rogers, R. R. and Yau, M. K.: A Short Course in Cloud Physics, 3rd Edn. Permagon Press, 304 pp., 1989.

Steenburgh, J., Campbell, L., and Veals, P.: North Redfield Snow Study Station Data. Version 1.0, UCAR/NCAR - Earth Observing Laboratory, https://doi.org/10.5065/D68051CN, 2014.

Stickel, J., Maloney, B., Pape, C., and Burkheimer, D.: Evaluation of the hotplate snow gauge, Center for Transportation Research and Education, Iowa State University, Aurora Project 2004-01, 2005.

Thériault, J. M., Rasmussen, R., Ikeda, K., and Landolt, S.: Dependence of snow gauge collection efficiency on snowflake characteristics, J. Appl. Meteorol. Clim., 51, 745-762, 2012.

Warnick, C. C.: Rime ice and snow capping on high altitude precipitation gages, Proceedings of the 25th Annual Western Snow Conference, Santa Barbara, California, Western Snow Conference, 24-34, 1957.

Weast, R. C. (Ed.): Handbook of Chemistry and Physics, 56th Edn., Chemical Rubber Company, 2350 pp., 1975.

Wettlaufer, A.: A fully compensated algorithm for the hotplate precipitation sensor, MS Thesis, Department of Atmospheric Science, University of Wyoming, 2013. 
Wettlaufer, A. and Snider, J. R.: University of Wyoming North Redfield Hotplate Processed and Time Series Data, Version 1.0, UCAR/NCAR - Earth Observing Laboratory, https://doi.org/10.5065/D6P26WWH, 2015.

Wolfe, J. P. and Snider, J. R.: A Relationship between Reflectivity and Snow Rate for a High-Altitude S-Band Radar, J. Appl. Meteorol. Clim., 51, 1111-1128, 2012.
YES: INC., TPS-3100 Total Precipitation Sensor, Installation and User Guide, Version 2.0, Rev M, 43 pp., 2011.

Young, H. D.: Statistical Treatment of Experimental Data, McGrawHill Book Company, 172 pp., 1962. 